\title{
Reproducción de una identidad comarcal y exaltación de un vino: la Fiesta de la Vendimia de
} Toro

Reproduction of a regional identity and exaltation of a wine: the Festival of the Grape Harvest off Toro

Maria Pilar Panero García

\section{OpenEdition}

\section{Journals}

Edición electrónica

URL: http://journals.openedition.org/aam/349

DOI: $10.4000 /$ aam.349

ISSN: 2038-3215

Editor

Dipartimento Culture e Società - Università di Palermo

\section{Referencia electrónica}

Maria Pilar Panero García, « Reproducción de una identidad comarcal y exaltación de un vino: la Fiesta de la Vendimia de Toro », Archivio antropologico mediterraneo [Online], Anno XXI, n. 20 (1) | 2018, online dal 30 juin 2018, consultato il 03 janvier 2020. URL : http://journals.openedition.org/aam/349 ; DOI : 10.4000/aam.349

Este documento fue generado automáticamente el 3 enero 2020.

Archivio antropologico mediterraneo 


\title{
Reproducción de una identidad comarcal y exaltación de un vino: la Fiesta de la Vendimia de Toro
}

\author{
Reproduction of a regional identity and exaltation of a wine: the Festival of the \\ Grape Harvest off Toro
}

Maria Pilar Panero García

\section{NOTA DEL AUTOR}

Este artículo es un extracto actualizado de «La Fiesta de la Vendimia de Toro», realizado por M ${ }^{a}$ Pilar Panero dentro del Proyecto de investigación de la Dirección de Bienes Culturales de la Consejería de Cultura, Comercio y Turismo de la Junta de Castilla y León y la Universidad de Valladolid dirigido por José Luis Alonso Ponga: Manifestaciones festivas en Castilla y León: estrategias para documentación y protección de festividades; y desarrollo y aplicación práctica sobre el territorio, 15/09/2009-15/03/2010.

Deseo mostrar mi gratitud a Luis Segovia Lorenzo, a Benito Vega Ramos y a $\mathrm{M}^{\mathrm{a}} \mathrm{del}$ Canto López Riesco, a Francisca Hernández López, Concejala de Festejos, Bienestar Social y Participación Ciudadana de 2003 a 2011, y a mis queridos amigos Cristina Prieto Viñas y Javier Cantoral Fernández

\section{Introducción}

Cuatro son las celebraciones que con la designación de Fiesta de la Vendimia encontramos en la Denominación de Origen Toro. La primera en importancia y más antigua, a pesar de ser una fiesta joven, es la de la propia cabecera de comarca, Toro, y las otras se celebran en Morales de Toro, y desde hace menos años en Sanzoles, desde 2001, y en Venialbo, desde 2006. En estos cuatro casos las fiestas son de tradición muy 
reciente, pues las personas de la D. O. Toro que hemos entrevistado vinculadas al cultivo de la vid tienen la percepción de que antes la fiesta era la propia vendimia. Para su comprensión debemos tener presente las circunstancias y el contexto en el que han nacido y se desarrollan. La Fiesta de la Vendimia de Toro forma parte una corriente que, por un lado, recupera fiestas antiguas y, por otro, crea nuevas celebraciones que tienen como base la gastronomía o la historia. Esta tendencia, que se inició en las últimas décadas del siglo pasado, continúa actualmente (Alonso Ponga 2016).

2 Las fiestas del vino, en general, son comunes a todas las denominaciones de origen, forman parte de un horizonte festivo en el que la sociedad, sobre todo la sociedad urbana, y más frecuentemente la sociedad urbana emigrada del mundo rural, comenzó a utilizar la gastronomía en las reuniones periódicas que hacían en los lugares de destino como un recordatorio evocativo de las tierras que habían abandonado. Este primer paso se refuerza sobre todo en las denominadas "casas regionales", en las que eleva a la categoría de emblemáticos los productos producidos en la provincia, o en la región, y que sirven como refuerzo de nostalgias y exaltación de productos pretendidamente autóctonos. El nombre que hará furor es precisamente el de exaltación . En estas fiestas lo que se pretende realzar es un producto considerado como típico, que se presenta como algo naturalmente bueno porque es tradicional $\mathrm{y}$, sobre todo, porque opera como una seña de identidad por oposición a otros productos más modernos y de moda, o simplemente más universales.

3 El consumo de vino ha disminuido en los países productores, mientras que ha aumentado en los que no lo son y esta tendencia, que se inició en los últimos años del siglo XX, se mantiene en la actualidad (Elías Pastor 2005: 82-83) ${ }^{1}$. Cuando la sociedad dejó de ser eminentemente rural para convertirse en urbana desapareció la utilización del recurso del vino como alimento y medicina, que era como se utilizaba en las economías depauperadas. Por fortuna, la situación ha dado un giro de ciento ochenta grados y ya no existe la carestía de tiempos pasados, aunque no remotos, por lo que el vino, ha dejado de ser un artículo de primera necesidad por su aporte calórico para convertirse en muchos casos en un bien de lujo que se acoge dentro y se proyecta fuera como emblema de la comunidad:

Y no sólo somos lo que comemos porque los alimentos que ingerimos proporcionan a nuestro cuerpo las sustancias bioquímicas y la energía necesaria para subsistir, adquiriendo con ello sus propiedades físicas, sino porque la incorporación de alimentos supone también la incorporación de sus propiedades morales y comportamentales, contribuyendo así a conformar nuestra identidad individual y cultural (Contreras Hernández, Gracia Arnáiz 2005: 36).

4 Se ha pasado de la idea de la existencia de vinos mejores y peores a categorizar una serie de vinos como la suma de la perfección y desde estos se construye una gradación en la que los vinos de mesa no solo están en lo más bajo, sino que incluso son denostados. Precisamente en el momento en el que menos vino se consume en favor del de la cerveza y todo tipo de refrescos no alcohólicos es cuando este producto es más venerado (Elías Pastor 2005: 81-98).

5 A pesar de esta realidad que se puede constatar con los datos estadísticos en las fiestas de la vendimia, y la de Toro no es una excepción, se glorifica el consumo de vino y se ensalza la tradición en la producción de los caldos, aunque, evidentemente, los vinos que se producen actualmente son vinos de factura industrial porque se elaboran en bodegas modernas y con procedimientos que distan mucho de los de la vinificación tradicional. Las fiestas del vino, por lo tanto, forman parte de un horizonte mucho más 
amplio de revalorizar productos autóctonos $\mathrm{y}$, como todas las demás que exaltan cualquier "producto típico", son creaciones de una sociedad en la que dichos productos han perdido el valor y sentido que tuvieron en la sociedad tradicional para convertirse en productos escasos, en los que la preparación se hace al "estilo tradicional", aunque esto sea una falacia si nos atenemos a la realidad.

Existe la pretensión de que estos festejos sean el rito que dé comienzo a la vendimia, pero en realidad solo es un acontecimiento festivo. No faltan algunos comentaristas para quienes este momento es un recuerdo de la época en la que los toresanos comenzaban la vendimia y la entrada de los carros con los cestos y las uvas recién cortadas, era el momento esperado por los que quedaban en el pueblo pues los vendimiadores obsequiaban a los vecinos, y sobre todo a los niños, con los mejores racimos. Por ejemplo, para los participantes en la fiesta de Toro se evoca la celebración de la vendimia ancestral, pero lo cierto es que ésta se celebraba más tarde que actualmente debido a que el vino que se producía en Toro era un vino para la mezcla ${ }^{2}$, un vino gordo y fuerte con mucha graduación llegando a los $17^{\circ} \mathrm{o} 18^{\circ}$. Para que la uva madurara hasta alcanzar esta altísima graduación la vendimia era más tardía de lo que es hoy, pues los gustos y las necesidades han cambiado y se producen vinos más suaves $\mathrm{y}$ con muchos menos grados. Tradicionalmente el foco de la vendimia era por la Virgen del Pilar y ahora el foco la vendimia es aproximadamente un mes antes, sin embargo la fiesta se envuelve con un halo de nostalgia hacia un pasado ya superado.

7 En nuestra opinión el éxito avalado por la continuidad y la alta participación se basa precisamente en que el vino "no es un objeto de consumo normal" (Fischler 2005: 67) porque, además de cuestiones prácticas, es decir socioeconómicas y culturales e incluso políticas, para el consumidor moderno está dotado de una serie de valores evocativos, reales o imaginarios, que se construyen partiendo de la historia y de la cultura.

En esta puesta en escena colectiva aparecen también otras constantes como el intento de usufructuar el nombre de ese producto en beneficio de una localidad. Ésta se construye a sí misma buscando los valores que considera típicos y autóctonos, exaltando las diferencias. Sin embargo, todas estas diferencias son más aparentes que reales, hasta el punto de que las matrices sobre las que se elaboran las fiestas o son las mismas o varían muy poco entre sí en su planteamiento.

\section{La Fiesta de la Vendimia de Toro}

9 La Fiesta de la Vendimia de Toro es probablemente la manifestación popular más notoria y alegre de todas las que se producen en la ciudad. Se celebra, según el año, durante dos, tres o cuatro días de finalizando en domingo y siendo este último el más próximo a la Virgen del Pilar (12 de octubre) y pudiendo celebrarse en El Pilar, aunque lo más frecuente en los últimos años es que dure cuatro días comenzando el jueves y finalizando el domingo. Tiene su origen en el año 1972 cuando espontáneamente un grupo poco numeroso de personas se echó a la calle con dos carretas tiradas por tractores iniciando una celebración que se ha ido incrementando cada año, tanto en actos como en participantes. Esta fecha es reconocida tanto por las autoridades como por el pueblo de Toro como la del comienzo de esta fiesta considerada popular y tradicional.

10 El primer personaje de la corta historia de la Fiesta de la Vendimia es Rafael Martín Garduño, conocido popularmente por el mote familiar "Cirilo" y que falleció. Esta 
persona, recibió un homenaje en la edición de 2005 y en la edición de 2009 se relataba su labor en el programa oficial de este modo:

La pequeña historia de la Fiesta de la Vendimia toresana comienza inexcusablemente con la palabra: "Cirilo". Y ello porque nadie pone en duda que fue Rafael Martín Garduño, conocido como tal por circunstancias familiares, quien puso en movimiento el primer "carro engalanado" y lo paseó por las calles del pueblo, allá en 1972, suscitando la admiración de la gente pues, ya por entonces, carros y mulas habían perdido la batalla del acarreo y del transporte.

11 Otros personajes que salieron los primeros años y que desfilaban de forma particular son recordados en Toro. Con el tiempo fue el Ayuntamiento el que comenzó a intervenir para reforzar una fiesta popular en la que ninguno de los pioneros era agricultor. La fiesta tiene su origen en el desfile de carros, hoy conocido oficialmente como "Tradicional desfile de carros engalanados a la antigua usanza y cestas de vendimia", y esta formación cívica es el acto capital de la fiesta en la que con el paso del tiempo el número de actividades de las que se compone se han ido incrementando notoriamente. Como este acto es el esencial de la fiesta, y sin el que todos los demás carecen de sentido, volveremos más adelante sobre él.

12 La fiesta actual en su conjunto es la suma de diversas actividades culturales, lúdicas y deportivas ${ }^{3}$ que no tienen la misma importancia, no ocupan los mismos espacios y no van dirigidos al mismo público, pero que se distribuyen a lo largo de los cuatro días que suele durar la celebración, si bien los preparativos de la misma comienzan mucho tiempo antes.

13 La fiesta celebra en una apretadísima agenda jornadas gastronómicas en los restaurantes de la ciudad; uno de los llamados "mercados medievales" que durante tres o cuatro días permanece abierto al público y que se caracteriza porque en éste mercado prima lo comercial y porque habitualmente se encarga a una empresa que es la que contrata los espectáculos y demostraciones (oficios tradicionales) asociados al mercado, aunque se trata sobre todo de puestos de venta; el "Concurso Comarcal de Vinos Caseros. Premios Lagarejo" organizado por el Consejo Regulador que premia a los cinco mejores vinos caseros presentados a concurso; actuaciones de música tradicional a cargo de grupos folk muy conocidos; el Certamen de Pintura Rápida que aporta una nota alegre pues los pintores toman el centro de Toro con sus caballetes, lienzos y pinceles; la cata de vino de caldos producidos en bodegas adscritas al Consejo Regulador; otras actividades culturales que van desde actuaciones flamencas, representaciones teatrales, presentaciones de libros, conciertos de música clásica, pase de fotografías, coloquios o el certamen de dibujo y literatura organizado en los colegios de Toro; y diversas actividades deportivas como el Kilómetro Urbano, la Marcha de Montain Bike o el Torneo de Pádel.

14 El primer acto que da comienzo a estas actividades que conforman la fiesta en su conjunto es el Pregón oficial de la Fiesta de la Vendimia en el que una personalidad en presencia de las autoridades locales y de las invitadas, de los miembros del Consejo Regulador de la D. O. Toro, de los bodegueros y del público que desee asistir hasta completar el aforo del Teatro Latorre elogia siguiendo las pautas literarias del género las excelencias del vino de Toro y de su fiesta, de sus gentes y del lugar en general y todo ello trufado de experiencias personales. La elección de este personaje de reconocido prestigio profesional, y en muchos casos vinculado al vino de Toro o a la ciudad, es del interés del público en general y se suele reflejar en la prensa regional. A continuación se desarrolla una de las muchas actuaciones musicales que se sucederán 
esos días a cargo de una agrupación de la ciudad. El pregón junto con el Tradicional Desfile de Carros, que es el acto popular cardinal, es el más importante de los oficiales o institucionales. El pregón abre la fiesta mientras que el desfile y el comensalismo posterior la cierra a pesar de que pueda haber programadas algunas actividades después del mismo4. Además el hecho de que la participación en las actividades sea una decisión libre y voluntaria, les otorga la categoría de juego en el que el hedonismo tiene su lugar, pero al mismo tiempo prima la operatividad, es decir, que si algo no funciona se elimina simplemente, por lo que la fiesta en su conjunto es un material elástico y variable que se utiliza para el desarrollo y el progreso de la cultura que lo genera.

\section{Niveles de la fiesta}

En general, se trata de una fiesta que opera a tres niveles: como fiesta de un producto con denominación de origen que, consciente o inconscientemente, se relaciona con el mismo producto de otras denominaciones de origen, y por lo tanto entra en una lucha simbólica por el dominio del mismo en el mercado nacional o internacional, como fiesta comarcal y como fiesta local. La fiesta está abierta a los forasteros no sólo para el desfile de caros y éstos, sobre todo si son del alfoz se animan a participar en las numerosas actividades programadas.

Se puede afirmar que el papel de Toro en este caso es del líder del alfoz porque, en la ciudad se ritualizan las cualidades y los valores de una identidad étnica basada en su producto más emblemático, el vino, apelando a la autenticidad del producto que se legitima en la Historia.

En la fiesta se reproducen las identidades comarcales y en este contexto Toro, como cabeza de un extenso alfoz, sale reforzado en su relación con los demás pueblos de la comarca. No se establece una lucha entre la cabecera de comarca y los pueblos de los alrededores, se establece un refuerzo del papel director que tiene esta ciudad sobre los territorios vecinos. El vino, es la base indiscutible de una economía en la que es importante no solamente el vino como producto comercial, sino también como un elemento que cimienta la autoestima de un territorio, y como generador de otras riquezas subsidiarias como es el turismo. La participación de algunos vecinos de otros lugares limítrofes en la fiesta en general y en el desfile en particular, pone de manifiesto el papel central de la ciudad de Toro, que en este caso ejerce de anfitriona en un contexto de unidad comarcal, independientemente de las rivalidades lógicas y habituales entre poblaciones cercanas.

Toro ejerce de modelo que se imita en los otros lugares de la Denominación de Origen en los que se celebra esta fiesta de factura moderna suplantando a otras más antiguas ${ }^{5}$, como sucede habitualmente en las reinterpretaciones folklorísticas. Éstas tienen su origen y relación con el folkore, pero mezclan la veneración a la disciplina académica que investiga la cultura tradicional, sobre todo la etnografía, con una predisposición a la acción que parte de una sensibilidad social hacia la tradición y las formas arcaicas de la cultura (Martí: 1986 passim). 


\section{El “Tradicional desfile de carros engalanados a la antigua usanza y cestas de vendimia"}

19 La parte más esperada de la Fiesta de la Vendimia es el desfile que se celebra el domingo por la mañana y en el que se reproducen desde las identidades grupales de Toro hasta algunas identidades provinciales. Los "trajes típicos", las orquestas, los aperos antiguos, las comparsas que desfilan en otros momentos se integran en la exaltación del vino. Es la actividad más participativa, vistosa y bulliciosa y, también, la que dio origen a la fiesta y la que, en buena medida, justifica la existencia de las demás actividades. Se podría prescindir de cualquier otra, incluso del pregón oficial, pero no de este desfile. Este desfile es el clímax y, de alguna manera, el final de la celebración, aunque haya actividades el resto del domingo, que es el día en el que siempre se celebra.

20 Sin este desfile la Fiesta de la Vendimia sería una de las tantas fiestas de vendimia que discurren en los meses de septiembre y octubre, porque la concepción de la fiesta es idéntica a todas las que exaltan el vino $u$ otros productos alimentarios. Insistimos en que se enaltece, más que un hecho concreto, un continuum histórico, la antigüedad y abolengo de una D. O. histórica. Aquí se olvida intencionadamente, aunque no de forma malintencionada, los retrocesos en cuanto al cultivo de la vid y la producción de vino que se han dado en la zona (Moreno de la Torre 1990: 147; Calvo Madroño 1914: 78-79, 284-286). El discurso historicista se sustenta sobre falsas asociaciones en las que se presupone que podemos revivir las vivencias y sensaciones de los antepasados. Se trata por lo tanto de un discurso lineal, evolucionista, fácilmente asimilable.

21 La diferencia entre esta celebración y otras es el esfuerzo técnico y estético que supone el desfile y gracias a este acto y a la calidad del mismo la celebración fue declarada de Interés Turístico Regional en 2003, hecho que todos los informantes valoran porque sienten que esto es un logro colectivo. Esta valoración la transmiten con uno de los nombres no oficiales, pero sí oficioso de la fiesta, "El desfile de carros".

22 La fiesta en su día principal, el domingo, con la celebración del desfile congrega según los datos de 2008 a 15.000 personas $^{6}$. Esta reunión con una participación masiva de los toresanos ha alcanzado un alto nivel de popularidad en los pueblos del alfoz. Estos últimos años han desfilado vecinos de Morales de Toro, Pinilla de Toro, Vedezmarban, Valdefinjas, El Pego, La Bóveda de Toro, San Román de Hornija que lo hacen con carros o con cestas. Para presenciar principalmente el desfile hasta Toro se desplazan grupos de distintos lugares de la provincia, de la comunidad autónoma y de otras zonas de España. Se trata de una fiesta que no ofrece ninguna restricción especial para los forasteros por lo que cualquier persona que se adapte a las normas puede participar.

23 Los participantes se inscriben en la Oficina de Turismo cuando concluyen las fiestas de San Agustín, a finales de agosto, a través de una persona que lo hace en representación de cada carro o grupo. Es curioso que la inscripción se haga tras finalizar las fiestas de verano en las que también se ensalza el producto glorificado, pues es precisamente en San Agustín cuando se celebra la popular "fuente de vino"7. Es decir, se termina con una exaltación del vino para pensar en la siguiente. Los participantes se congregan en la Plaza de San Francisco para desfilar hacia las 12 horas y con sus carros y sus cestas emulan un mundo extinto e idílico. El itinerario, que se ha modificado desde 2004 con el fin de que haya espacio suficiente para que los carros cada año más numerosos, aunque 
no hay datos oficiales acerca del número de personas que desfilan, no se aglutinen y el desfile sea más cómodo. Parten de la ya citada Plaza de San Francisco y sigue por la Calle Rejadorada por delante del Hospital de la Cruz, Calle El Sol, Plaza de Santa Marina (vuelta), Arco del Reloj, Puerta del Mercado y finaliza en el epicentro de la ciudad, la Plaza Mayor. Se utiliza el espacio público y más céntrico de la ciudad histórica pues el desfile trascurre entre el segundo recinto amurallado y el primero que tuvo la ciudad. Al concluir el desfile se entregan los siguientes premios: placa al mejor carro engalanado, Premios Lagarejo, premio a la mejor cesta de vendimia, que desde 2009 también tiene categoría infantil, premio al mejor concurso de escaparates y se hace además un homenaje a distintos vecinos que han contribuido a que esta fiesta sea una realidad con futuro.

24 La organización del desfile corre a cargo del Ayuntamiento y es éste a través de la Comisión de Festejos el que decide el orden de salida de los inscritos, orden que los participantes desconocen hasta prácticamente la salida. Esto es así por una cuestión pragmática, pues es el modo más sencillo para que el desfile no le resulte monótono a los espectadores y así gozar de más libertad los organizadores a la hora de intercalar grupos con carro y grupos con cesta con comparsas musicales y asociaciones ${ }^{8}$ que desfilan, aunque siempre se cierra con las damas de las fiestas de San Agustín, la Comisión de Festejos y la Banda Municipal de Música de Toro, La Lira. Al terminar su recorrido son también los organizadores los que indican el lugar exacto en el que cada carro se debe colocar en la Plaza.

Cuando los participantes en el desfile y el resto del público llegan a la Plaza Mayor el producto, que ha sido "pregonado" dentro de la corriente actual de que no puede haber exaltación de un producto si no es elogiado por una personalidad, es recibido por las autoridades locales y las invitadas $\mathrm{y}$, tras la breve proclama institucional, pues la arenga ya se ha hecho extensamente en el Pregón Oficial, se hace entrega de los galardones y culmina el ritual de la fiesta con la degustación de los caldos y otros productos locales. De hecho la subvención que recibe cada carro que se inscribe y participa es en especie (queso, pan y vino) se hace con el objeto de que la llegar a la plaza se compartan estas viandas con todos los asistentes y el comensalismo sea global. Además se consumen las que llevan en las cestas de vendimia que son una aportación particular de los actores que desfilan. Cuando termina la actividad en la Plaza Mayor muchos grupos se trasladan con su carro a comer en propiedades particulares o en otros espacios públicos. Los grandes acontecimientos para los grupos, como este de fortalecimiento comunitario, siempre se han celebrado con banquetes.

\section{Los elementos del desfile: los animales y aperos, la indumentaria y la música}

Existe un acuerdo tácito entre los organizadores y los participantes acerca de la manera de desfilar, de modo que todos aquellos que desfilan ya saben que deben hacerlo y cumplir unas normas que no están escritas, pero que se presupone todos conocen. Al exaltarse una pretendida cultura popular se echa mano de un folklore descontextualizado, que es mera exaltación de lo local en la que no faltan canciones e instrumentos, indumentaria tradicional y aperos de labranza, sobre todo los carros, antes tan necesarios en el transporte de las uvas a la bodega. Para la exhibición pública del vino se utilizan fósiles culturales que han adquirido la categoría de emblemas de la 
ciudad. No se ha producido una revitalización de la vendimia tradicional para construir la fiesta basada en un estudio histórico, sino que se ha basado en la consideración del público y de los actores que desfilan, por lo cual el hecho de valorar la importancia que han tenido el vino en la construcción económica y cultural del ayer y del hoy se percibe bajo una óptica romántica.

Según las autoridades existe un interés continuado por mejorar la performance folklórica y se habla de "cumplir normas", de asistir "debidamente ataviados" e incluso existen asesores labradores que orientan a los participantes en las tareas de atar a los animales, etc. y que además determinan cual es el mejor carro en el concurso. El incumplimiento de las reglas como desfilar con calzado deportivo, con un carro con las llantas de las ruedas de goma, puede suponer la pérdida de la subvención o incluso la imposibilidad de desfilar, aunque hay otros detalles menos llamativos que se pasan por alto. Al no estar esas normas escritas y no constreñir demasiado a los participantes, especialmente los que desfilan con carro, existe un margen de libertad amplio en la forma de desfilar. El rigor etnohistórico no existe, pero esta ausencia se justifica en favor de la espontaneidad y con el afán muy loable de los participantes por aprender y mejorar cada año. Con esto no queremos decir que el espectáculo se desmejore porque, si bien es cierto que la documentación etnográfica sería mejorable, no lo es la conciencia de veracidad de lo que se representa o se ve, pues para el gran público se produce una representación sincera de su cultura enológica que se percibe como ancestral e incluso atávica.

Cuando un espectador cualquiera presencia el desfile lo que primero llama la atención es el barroquismo con el que carros y cestas se engalanan. Esto forma parte del acuerdo implícito por el que los actores saben que lo que celebran es la abundancia que el vino ha dado a todos los que han vivido de él. Los carros van repletos de cestos cargados de uvas, una selección de los frutos más lustrosos y hermosos que ofrece el otoño calabazas, calabacines, granadas, manzanas, pimientos, algún tomate tardío, etc. - y de objetos de lo más variopinto, que en unos casos sin duda sí se llevaban por necesidad a los pagos donde estaba la viña como por ejemplo las sartenes de tres patas en las que se preparaba el fricandón ${ }^{9}$, las cuernas para llevar condimentos como la sal o el pimentón, calabazas para almacenar agua..., mientras que en otros son objetos que con buen criterio no se llevaban a vendimiar porque no eran útiles como manillas de puertas, almadreñas, fanegas, sillas, escobas de barrer, escobos de limpiar las cubas. En general se ata a los carros todo aquello que le de un halo de envejecimiento o productos que se entiende son de siempre como una presa de conejo, el hueso de un jamón, ristras de chorizos. En las cestas se transportan todo tipo de viandas crudas como frutas y cocinadas como guisos, torreznillos, rosquillas.

Los carros son movidos por animales de tiro, si bien en la agricultura tradicional había muchos tipos de economías que condicionaban la utilización de unos animales u otros o de tractores. En la memoria se conservan los testimonios que relatan como el laboreo de la tierra y el transporte en ocasiones se hacía con parejas de bueyes, y muchos agricultores dan testimonio de que trabajaron con burros, con mulas, con machos burreños o con mulas mohínas hasta que pudieron comprar su primer tractor. Es precisamente cuando la fiesta empieza a cobrar relevancia y cuando sus participantes toman conciencia de lo que celebran, cuando se empieza a cuidar el uso de animales en el desfile. Ésta nace como una celebración espontánea e ingenua abanderada por unos particulares, probablemente con la única finalidad que la diversión, que desfilaron con 
dos carrozas tiradas por tractores. Ahora los pioneros no podrían desfilar de esa guisa pues solo se permite el desfile a carros tirados por animales, propios o alquilados. También se permite desfilar con animales de recreo y en ocasiones ha desfilado algún pony o algún perro. La organización y los participantes llevan unos años trabajando para que gracias a los animales el desfile resulte más estético.

Desde las últimas ediciones de la fiesta se busca además que los animales vayan limpios y engalanados porque, aparte del factor pintoresco que en este desfile está muy presente, los animales tradicionalmente en el agro han contribuido a la supervivencia y al bienestar del hombre. No se puede olvidar también que a través de ellos y de su ornato éste ha demostrado su estatus y poderío económico.

Otra de las directrices para desfilar es la correcta indumentaria, pues se les exige a todos los que participan que lo hagan con atuendos tradicionales. Por estos nos referimos a los fósiles en los que se convirtieron tras los profundos cambios sociales que se iniciaron después de la Guerra Civil y se consolidaron en los años 60 y 70 del pasado siglo con el triunfo del modelo urbano sobre el rural, aunque el declive de estos vestidos se había iniciado mucho antes cuando dejan de servir para lo que fueron creadas, para vestir. Los llamados trajes típicos son objetos que identifican con facilidad a una comunidad desde dentro y desde fuera y están presentes desde hace años en muchos contextos en los que no se utilizaban como por ejemplo para celebrar el Carnaval, en ofrendas a la Virgen, los santos, Jesucristo,... En el desfile vemos a mujeres y a niñas ataviadas con originales o copias de los hermosos trajes toresanos de viuda rica o de labradora o lo que se denomina "traje castellano", aunque no se sepa muy bien que hay detrás esa última etiqueta; sin embargo entra dentro del sentido común pensar que a ninguna mujer en su sano juicio se le ocurriría ir a vendimiar de esa guisa por dos razones, la primera porque no sería cómodo y la segundo porque sería el modo de desbaratar unas prendas ricas que sí se utilizaban en otros contextos. Además de desfilar con estas joyas del vestido que se han guardado durante años en los baúles o que se han reproducido recientemente con esfuerzo, hay muchas mujeres que lo hacen con el que se supone que sí era el traje de vendimia, aunque en su mayoría han sido creados para la ocasión. Apenas se conservan trajes de faena originales por su deterioro y por el escaso valor que se les ha dado y aquí también se deja actuar según el criterio de los participantes.

32 Los hombres desfilan con el traje de labor, aunque aquí, al igual que en el femenino sean creaciones nuevas. En general, en los varones prima el transmitir al espectador una rudeza masculina que se asocia con el antaño. En algún caso puntual se cae en un estereotipo de lo rural, que tiene una carga agresiva porque deshumaniza y degrada, y algún hombre acompañan este atuendo con maquillaje para simular el carácter rustico y desaliñado que se le presupone, por supuesto falazmente, a los campesinos y se pintan cejas prominentes o coloretes. También hay otras excepciones y los hombres de alguna asociación como la de los Amigos de la Capa desfilan vestidos con traje y corbata modernos sobre los que llevan una capa, la prenda de más empaque de la indumentaria masculina se recicla para reivindicar las labores agrícolas de antaño, aunque sus acompañantes femeninas sí desfilan ataviadas con trajes populares y con mantones de Manila.

33 Además del colorido que aporta la indumentaria local ésta se enriquece con el que aportan las agrupaciones de folklore que desfilan como comparsas musicales y que se desplazan de la capital ataviadas con trajes sobre todo, alistanos y de carbajalina. 
Aunque hay que destacar que el colorido lo aportan, sobre todo, los trajes femeninos, pues en los de los varones prima la estandarización que se llevó a cabo de los mismos en España tras la labor de recuperación de la Sección Femenina y, excepto algún elemento más característico como la montera que se utilizaba en Aliste, parecen uniformados para bailar ${ }^{10}$.

34 La música de marcado carácter provincial es el tercer elemento, junto con aperos e indumentaria, con el que se pretende dar al evento una atmósfera añosa. Intercalar comparsas musicales entre los demás participantes es una forma de romper la monotonía y, de hecho, cuantas más personas se inscriben para desfilar con carro, con cesta o como colectivo más música hay en el desfile. Participan diversos grupos de toda la provincia de Zamora y que tocan algunos instrumentos que no están adscritos al ámbito de Toro como la gaita de fole, pero no importa pues la música aporta una buena dosis de algarabía y mayor interés al desfile independientemente de su procedencia. El desfile lo abre un tamborilero toresano, Modesto, lo cierra la Banda Municipal de Toro, La Lira, y participan además los integrantes del taller de música tradicional que puso en marcha la Concejalía de Cultura de la ciudad. Durante el desfile se entonan una serie de canciones de vendimia siendo la más emblemática y conocida "Tío Babú".

\section{El sentido del desfile}

La evolución del mito que se festeja en este caso tiene que ver con la evolución de la fiesta. Curiosamente los pioneros de la fiesta no se dedicaron profesionalmente a la agricultura, aunque por su extracción rural es más que probable que, como la mayor parte de los habitantes que en la época vivían en el campo en España, tuviesen un conocimiento considerable de las labores agrícolas. Sin embargo, esta visión naif de la vendimia tradicional, precisamente cuando la mecanización llega masivamente al campo español (recordemos que ellos desfilan con tractor y carroza y no con carro de tracción animal como se hace ahora) está en los parámetros de la percepción del tiempo pasado.

Es frecuente que, cuando se produce una tendencia a la homogeneización, se reivindique lo diferencial precisamente por las clases que no dependen económicamente de de aquello que se añora. La conciencia de la pérdida de la cultura tradicional siempre ha partido de los sectores más progresistas de la elite cultural.

Es precisamente cuando se habla con personas que han vivido de la agricultura hasta su jubilación o que incluso se dedican a ello actualmente cuando, aunque reconocen la parte lúdica de la vendimia, destacan abiertamente su dureza, sobre todo porque al mismo tiempo que se recogía el fruto estaba la premura de encerrarlo en la bodega para evitar que se desbaratase. Sus comentarios distan mucho de de la visión idílica que ofrece la Fiesta de la vendimia que es intento de recrear unas tradiciones, pero no desde la etnohistoria, sino desde la mitificación de e unos valores que se recuerdan en la lejanía y que se valoran como testimonios de un tiempo pasado y un mundo mejor. Estas personas destacan aspectos positivos de unas labores que tuvieron un marcado carácter festivo, más por contraposición a las otras tareas agrícolas más arduas, las del verano, que porque en sí mismas fuesen fundamentalmente lúdicas y no laborales. También subrayan valores de comensalismo y de ayudas mutuas que se dieron, qué duda cabe, pero se dieron dentro de unos contextos muy determinados propios de las sociedades asimétricas en las que la explotación del pobre por parte de rico 
aprovechando contextos tradicionalmente lúdicos era una constante. Estas personas destacan la diversión en la viña, sí, pero también la precariedad de las vías para acceder en un término extensísimo en el que era necesario pernoctar habitualmente durante varios días en tudas, chozos o casas de campo sin comodidades, para recoger el fruto o en otras épocas cuando se hacían labores como la poda, las penurias para transportar la uva hasta las bodegas, etc. Ningún informante ha olvidado la penosa costumbre del rebusco, que hermanan lógicamente con la de espigar.

Tal vez el pueblo de Toro escenifique una venganza colectiva tras haber vencido esta fijación de sometimiento a unos medios de los cuales dependía su riqueza, pero a los que estaba sujeto por circunstancias laborales. Para ello dulcifica los aspectos más desagradables de las vivencias y se potencian las más lúdicas y gratas, es decir, se hace un retorno imaginativo al pasado que aporta además beneficios en dos sentidos, como catarsis colectiva y de superación de un modelo económico de subsistencia y como una fuente de riqueza a través del negocio del turismo. En el primer caso algunos, los ancianos y los que no lo son tanto, recobran sus infancias perdidas, las vivencias de sus primeros años de vida, y otros, los niños y los jóvenes, son inculturados y estiman más y mejor su patrimonio cultural cercano y valioso.

El "Tradicional desfile de carros engalanados y cestas de vendimia a la antigua usanza" tal vez debamos leerlo en la clave con la que apreciamos una representación dramática, más que como una historia de los tiempos pasados. Debemos aclarar que el epíteto dramática, que se asocia generalmente a la ficción, no le resta autenticidad pues, el carácter teatral y representativo es inherente al ser humano y éste no invalida la sinceridad de la representación:

La representación en si misma puede estar cargada de verdad, puede ser una auténtica representación de problemas o acontecimientos de la visa humana. Hemos dicho, además, que la vida social está llena necesariamente de elementos teatrales. Es más, el ser consciente de un evento, es en cierta manera, el empezar a representarlo. Nuestra actuación convencional, pautada, teatral, en ciertos momentos de la vida social, puede ser llevada a cabo de forma sincera y auténtica. Esta manera de actuar es la que honestamente debíamos llevar a cabo (Fernández de Rota 2010: 584-585).

La clave en este acto, que es un motivo de orgullo para muchos toresanos, está en el consenso y en el empeño por gozar con una historia cercana ya superada, pero que es preciso reorganizar por las necesidades del presente y la importancia que el vino tiene para la ciudad no es un hecho que no se deba tener en cuenta. El vino es el producto por el que Toro es mundialmente conocido en un tiempo en el las fronteras son más permeables que nunca. Es de notar que la ciudad, además de una notable enología, tiene otros muchos activos patrimoniales de diversa índole artísticos, históricos, festivos, lúdicos o lúdico-religiosos (Panero García 2012: 271), pero de todos ellos el que destaca y prevalece es el vino por ser sostenible, aplicable y versátil para combinar con todos los demás.

41 David Lowenthal desmenuzó de forma impecable todas las formas con las que podemos acceder al pasado y que se cumplen una a una en el desfile que ahora nos ocupa. En primer lugar se accede a través de la memoria, que puede tener un límite en la niñez de los interesados o remontarse al testimonio de los antepasados de estos, y en esta fiesta ésta juega un papel fundamental. Cuando se habla con personas que desfilan manifiestan su voluntad porque todo el desfile se desarrolle emulando lo que recuerdan o, si son demasiado jóvenes, lo que les han contado. En segundo lugar se accede a través 
de la historia y existen suficientes documentos que avalan la antigüedad del vino de Toro, aunque insistimos una vez más que en esta narración de continuidad existan lagunas que se olviden interesadamente $\mathrm{y}$ no perversamente. $\mathrm{Y}$ en tercer lugar rescatamos el pasado a través de las reliquias y ya hemos visto que en este desfile salen todas las que atañen a la vendimia, otras que no tienen nada que ver con ella como por ejemplo, los mantones de Manila, y otras que se presentan como tales, pero son réplicas de reliquias como maquetas de carros. Las reliquias son puentes con el pasado y precisan de una interpretación para que lo alumbren, es decir, para que activen las otras formas de acceder al mismo, la memoria y la historia (Lowenthal 1998: 269-375).

En realidad, se hace una puesta en escena prescindiendo en parte de una interpretación a favor de seguir unos patrones marcados por una idea sesgada, podemos volver a utilizar el término fosilizada, de la tradición que no debemos olvidar siempre es cambiante (Hobsbawm, Ranger: passim). Una representación dinámica como esta avoca a los participantes de la representación a incluir elementos innovadores para lograr que algo variable se perciba y asuma como tradicional: "Para ello no existen demostraciones racionales ni fórmulas indiscutibles, el único test de validación es el alto nivel de consentimiento colectivo" (Fernández de Rota 2010: 857).

La Fiesta de la Vendimia de Toro ha pasado a lo largo de sus cuarenta y cuatro ediciones de ser un celebración espontánea a ser una celebración tutelada por el poder local, pues el espectáculo folklórico siempre ha contado con el mecenazgo de los poderes fácticos y de la acción política, aunque esta dirección no hay que entenderla como constreñimiento al menos en la conmemoración que ahora nos atañe. Además del mecenazgo la temática de la fiesta tiene desde hace unos años el viento a su favor y cualquier empresa intelectual que adopte cualquier aspecto de la basta cultura del vino como leitmotiv tiene un porcentaje de éxito asegurado. El producto, que ya hemos dicho se consume cuantitativamente menos que en otras épocas, goza de un predicamento muy alto, tal vez excesivo pues se puede hablar de mitificación, y las pautas socioculturales que lo dirigen han tenido una rápida y amplia difusión que lo han convertido en un producto de moda, a pesar del riesgo que esto supone para la industria. El vino se ha "intelualizado" o "culturizado" (Contreras Hernández 2005: 53) y ya no es un producto omnipresente en todas mesas o lugares en los que existía un trabajo arduo como en la siega (Fidalgo Santamariña 1999: 44), para, en general, adscribirse a unos contextos muy concretos asociados al moderno concepto ocio.

Como toda fiesta, y especialmente el desfile, es una manifestación cultural compleja inmersa en la sociedad y en la economía que la funda y la reinventa cada año y en ella se ritualizan actitudes y cualidades y, lo más importante, valores. La fiesta es un modo de ejercer de toresano (incluimos aquí al alfoz) a la comunidad que no aparta a todos aquellos que están en la diáspora y retornan para asumir su papel de origen. La adhesión a la fiesta en su conjunto o a determinados actos que se pueden elegir libremente le confieren un carácter no normativo y es esta permisividad es la que contribuye a que cada año sea más participativa. Conviene aclarar que para los participantes el desfile actual es el mismo que el desfile de 1972 a pesar de que son conscientes de la evolución. Una fiesta cívica como esta totalmente dirigida, controlada y con carácter obligatorio la abocaría al fracaso o a un cambio tan radical que terminaría por desconocerse. 


\section{Conclusiones}

La justificación de esta celebración es una evocación nostálgica y deliberada de la vendimia, como parte de la historia de vida toresana, y ésta es asumida por todos los participantes y el público en general. Sin embargo, se evoca esta vida de antaño basada en unas realidades social, económica e ideológica que no son comparables a las nuestras, a las actuales, y que estaban llegando a su fin poco a poco desde los años 60 del pasado siglo, pero que sin embargo sí se observan desde el presente. De hecho esta fiesta en su conjunto, y esto ya lo hemos apuntado en varios lugares, parte de una necesidad de reorganizar el pasado desde el presente, porque las comunidades en general suelen esforzarse en construir un pasado digno y heroico que si es posible afiance la idea de continuidad a lo largo de la Historia.

Al mismo tiempo que se ensalza el producto se reviste el acontecimiento de todo un gran contexto pretendidamente autóctono. Se echa mano explícitamente de la tradición y del folklore, por supuesto descontextualizado, pues no importa que en origen los elementos constitutivos de la fiesta no tengan nada que ver entre sí, lo principal es el uso que se hace de ellos. Todo vale cuando se trata de justificar la puesta en escena de una fiesta creada ex novo, que se pretende ofrecer como auténtica, original y diferente a las que se hacen en otros lugares, y que además pretendemos que sea "la fiesta de siempre", tal y como se ha hecho desde tiempo inmemorial, tal y como dicta la costumbre.

El vino, que es parte de la construcción económica y patrimonial de la ciudad y su extenso alfoz, encarna en esta fiesta todos los valores de fecundidad y de trabajo que se le han atribuido a este producto desde antiguo y que una sociedad moderna encumbra. En la fiesta opera un fuerte sentimiento de identidad a pesar de la globalización imperante, que hace que se tienda a una homogeneización también en los hábitos alimentarios.

En buena parte la Fiesta de la Vendinia de Toro es una acción conservadora (en el sentido de atesorar) y divulgativa de la tradición, que auspiciada desde un carácter marcadamente urbano o moderno, representa una tradición cultural de marcado carácter rural. El resultado es una performance folklorística pues es inevitable en un desfile cívico con tantos agentes evitar la "contaminación" de la modernidad.

Aprovechando la idea forzada de tradición, es decir, aquella en la que todo lo antiguo (tradicional, rural) se percibe como moralmente mejor y ontológicamente contraria a lo moderno se representa la etnicidad, que sirve para reproducir las diversas identidades que conviven en Toro. Estas identidades se exhiben fundamentalmente por el género, el grupo de pertenencia o de núcleo de población de origen, pero todas se sustentan en "lo típico", aquello que proviene de la recuperación-distorsión del siglo pasado, pero no es baladí que debemos tener muy presente que "lo típico" sufre cambios semánticos y formales en base a unos intereses, que en este caso concreto, son fundamentalmente estéticos y turísticos. 


\section{BIBLIOGRAFÍA}

Alonso Ponga J. L., 2016 «Fiesta y Patrimonio en Castilla y León: consideraciones para tiempos nuevos», en L. Díaz de Viana y D. J. Vicente Blanco (eds), El Patrimonio cultural inmaterial de Castilla y León. Propuestas para un atlas etnográfico, CESIC, Madrid: 235-248.

Calvo Madroño I., 1914 Descripción geográfica, histórica y estadística de la provincia de Zamora, Librería General de Victoriano Suárez, Madrid.

Casero E., 2000 La España que bailó con Franco. Coros y danzas de la Sección Femenina, Nuevas Estructuras, Madrid.

Contreras Hernández J., 2005 «Los sentidos del vino: significados y sensaciones en un mundo globalizado», en J. Marcos Arévalo (ed.), Las culturas del vino. Del cultivo y la producción a la sociabilidad en el beber, Signatura Demos, Sevilla: 37-57.

Contreras Hernández J., Gracia Arnáiz M., 2005 Alimentación y cultura. Perspectivas antropológicas, Ariel, Barcelona.

Elías Pastor L. V., 2006 El turismo del vino. Otra experiencia de ocio, Universidad de Deusto, Bilbao.

Fernández de Rota y Monter J. A., 2010 «Autenticidad o simulacro: el patrimonio como puesta en escena cultural», en J. Marcos, S. Rodríguez y E. Luque (eds.), NOS-OTROS: miradas antropológicas sobre la diversidad, Asamblea de Extremadura, Mérida, vol. II: 849-862.

Filalgo Santamariña J. A., 1999 «Campesinos gallegos y las siegas en Castilla», en J. L. Alonso Ponga (coord.) Gallegos a Castilla. Segadores en Tierra de Campos, Taller de la Imagen, Valladolid: 37-46.

Fischler C., 2005 «Vino y cultura», en J. Marcos Arévalo (ed.), Las culturas del vino. Del cultivo y la producción a la sociabilidad en el beber, Signatura Demos, Sevilla: 59-68.

Hobsbawm E., Ranger T. (eds), 2002 La invención de la tradición, Crítica, Barcelona.

Lowenthal D., 1998 El pasado es un país extraño, Akal, Madrid.

Martí J., 1986 El Folklorismo: Uso y abuso de la tradición, Ronsel, Barcelona.

Moreno De La Torre A., 1990 Diario de Antonio Moreno de la Torre. Zamora, 1673-79. Vida cotidiana de una ciudad española durante el siglo XVII, F. J. Lorenzo Pinar y L. Vasallo Toranzo (eds.), Instituto de Estudios Zamoranos Florián de Ocampo, Zamora. 1990.

Panero García P., 2012 «Los guardas del campo de Toro: una mirada desde la Antropología», en Sueños de Plata. El Tiempo y los ritos. Fotografía y antropología en Castilla y León, Museo Etnográfico de Castilla y León: 265-283. Disponible en Internet en: Catálogo de imágenes, 206-224: http://museoetnografico.com/sdp_catalogo.php

Alonso Ponga J. L. (dir.), Panero García P., 2005-06 Instituto del Patrimonio Histórico Español y la Universidad de Valladolid. Estudio antropológico de las bodegas tradicionales de Toro y Tierra del Vino en Zamora. Inédito.

Alonso Ponga J. L. (dir.) et. al. , 2009-10 Proyecto del Instituto del Patrimonio Cultural de España «Documentación etnográfica en el área vinícola de la Denominación de Origen Toro» (Proyecto Nacional dirigido por M ${ }^{a}$ P. Timón Tiemblo y L. V. Elías Pastor: Atlas del cultivo tradicional del viñedo $y$ de sus paisajes singulares). Publicado parcialmente en:

Elías Pastor L.V., 2016 Atlas del cultivo tradicional del viñedo y de sus paisajes singulares, Madrid, 
Ministerio de Educación, Cultura y Deporte/ Ministerio de Agricultura y Pesca, Alimentación y Medio Ambiente. NIPO: 030-15-322-4 (Ministerio de Educación, Cultura y Deporte). NIPO: 280-15-237-3 (Ministerio de Agricultura y Pesca, Alimentación y Medio Ambiente). http://es.calameo.com/read/0000753359cdd1a3bf9bc

\section{ANEXOS}

1. Los pioneros, que desfilaron como les pareció oportuno en 1972, ahora tendrían que sustituir el tractor por animales

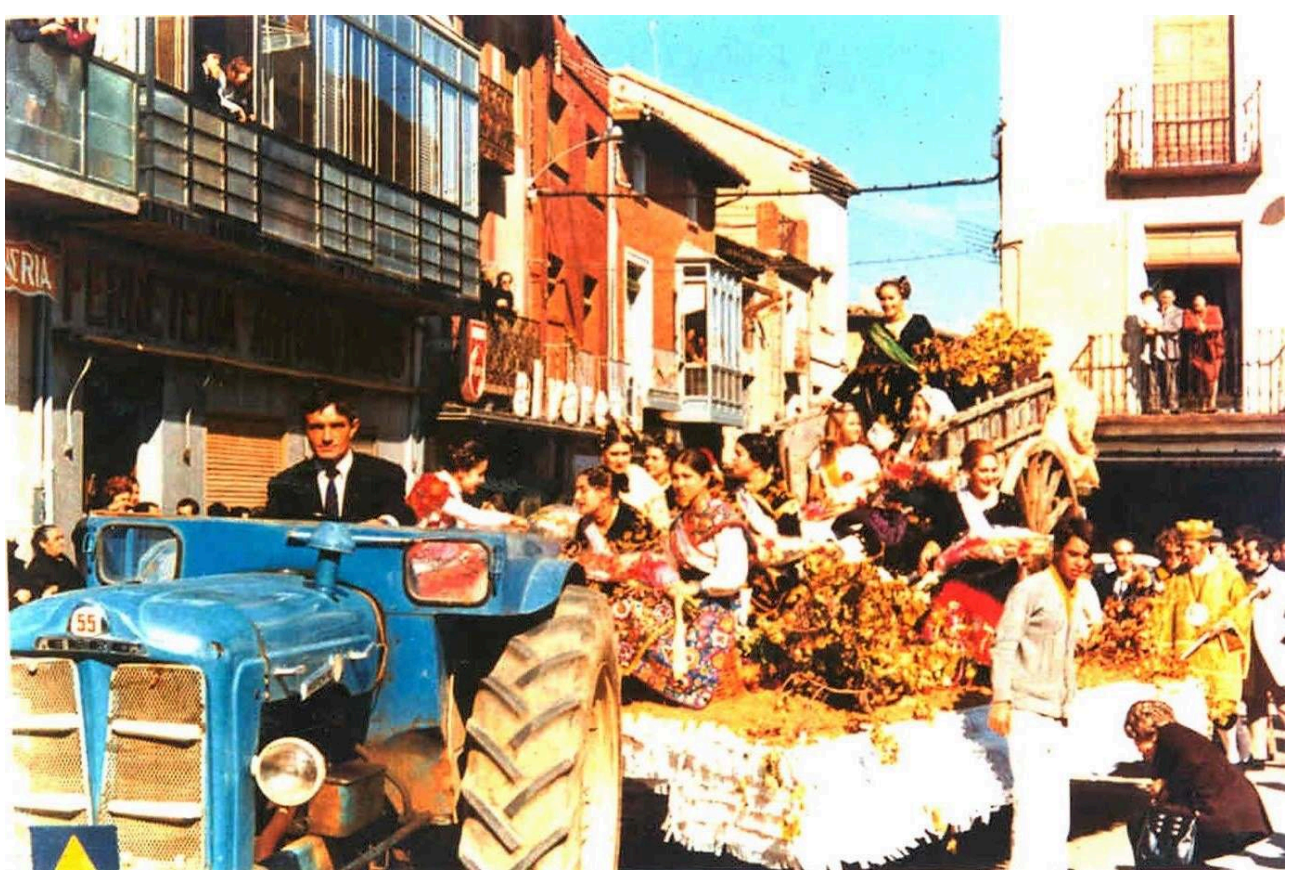

Fotografía gentileza de LA FAMILIA VEga RAMOS-LóPEZ RIESCo. 
2. Los pioneros, que desfilaron como les pareció oportuno en 1972, ahora tendrían que sustituir el tractor por animales

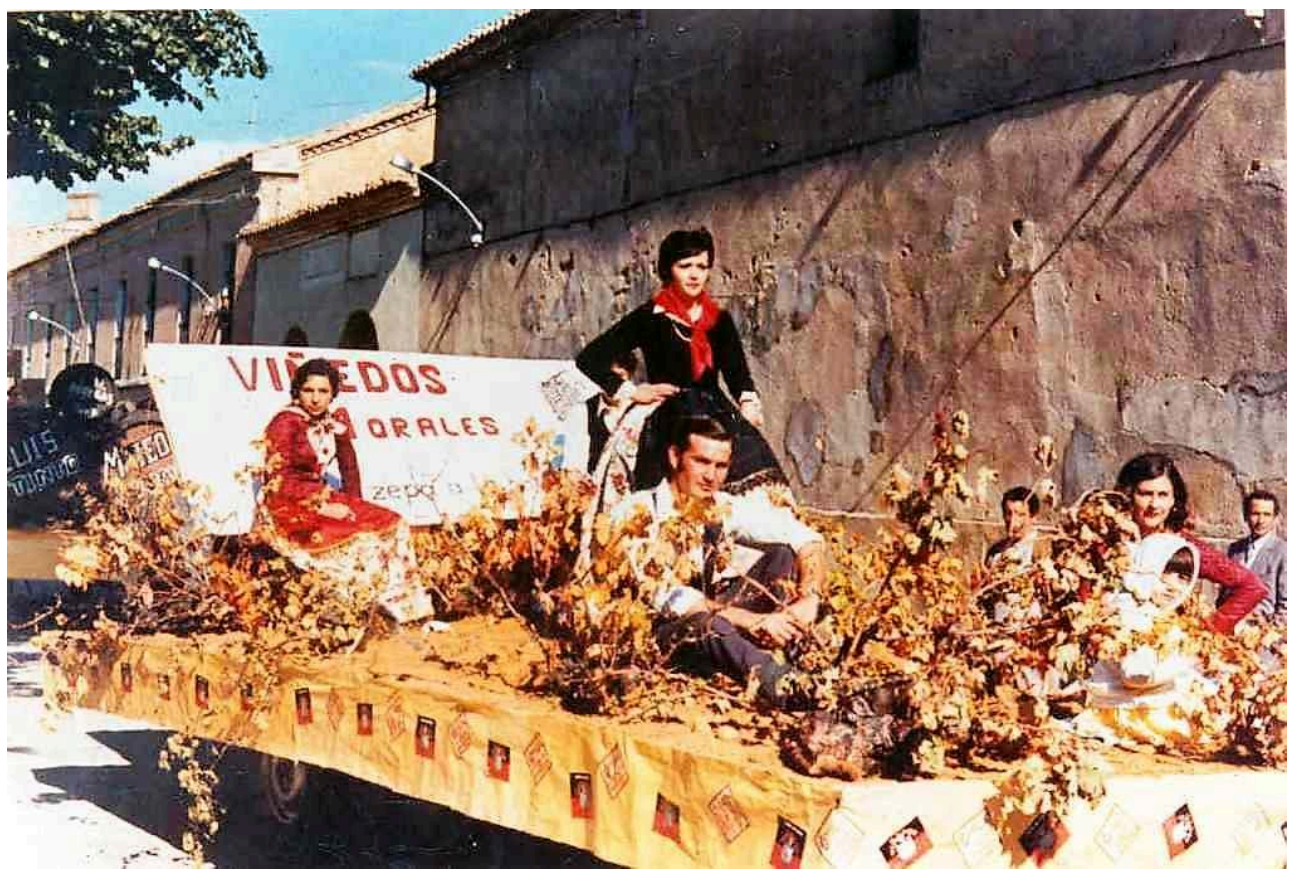

FOTOgRAFÍA gENTILEZA DE LA FAMILIA VEgA RAMOS-LÓPEZ RIESCO.

3. Carro repleto de viandas en la fiesta del año 2009 de la vecina localidad de Morales de Toro siguiendo el modelo de carro engalanado de la capital del alfoz

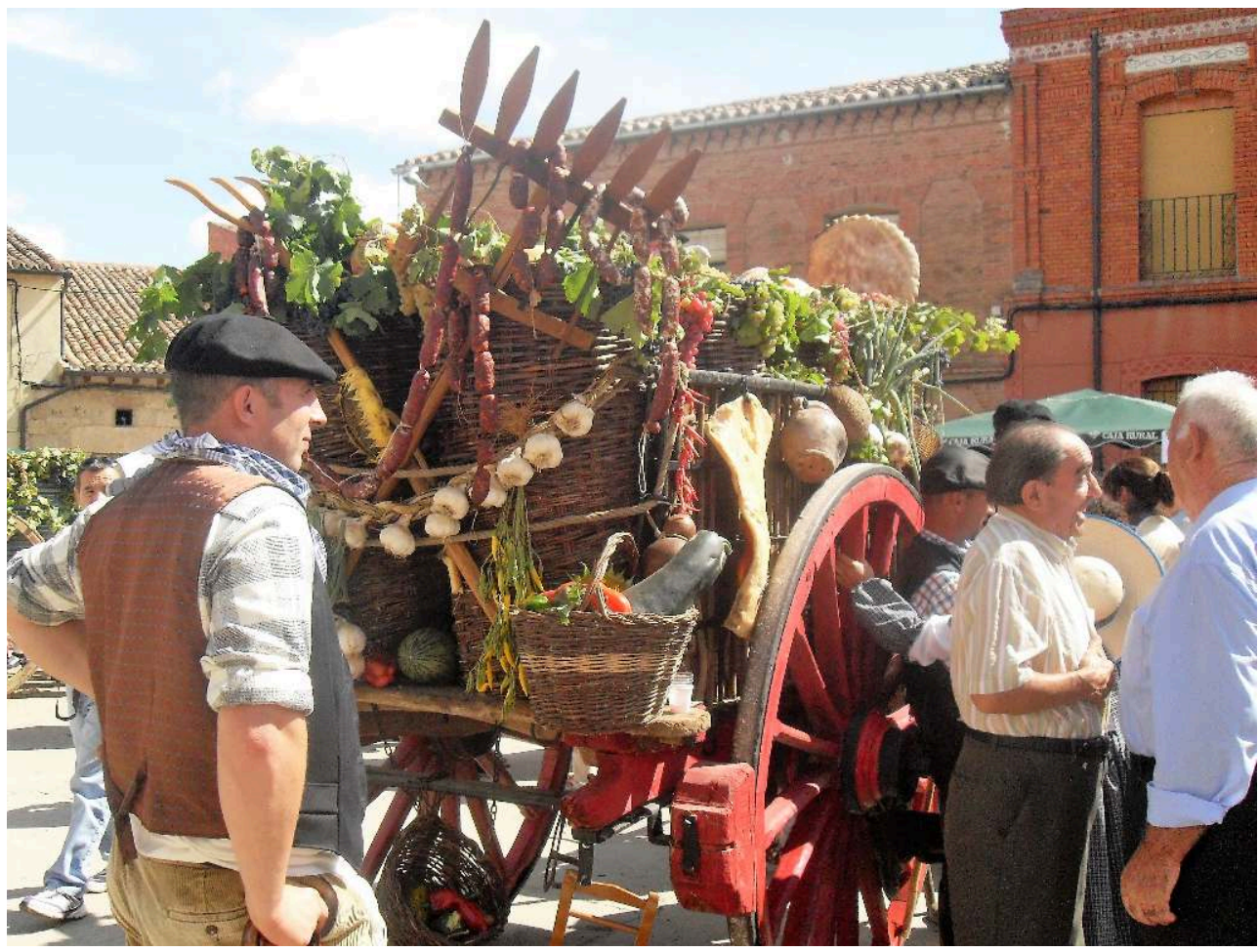

Al menos hasta el año 2005 no había carros engalanados en esta celebración. FOTOgRAFÍA DE LA AUTORA. 
4. Carros colmados de alimentos y objetos nada útiles en la vendimia tradicional, pero que se utilizan para hacer una evocación barroca del antaño y representar la riqueza que el vino ha proporcionado a los toresanos

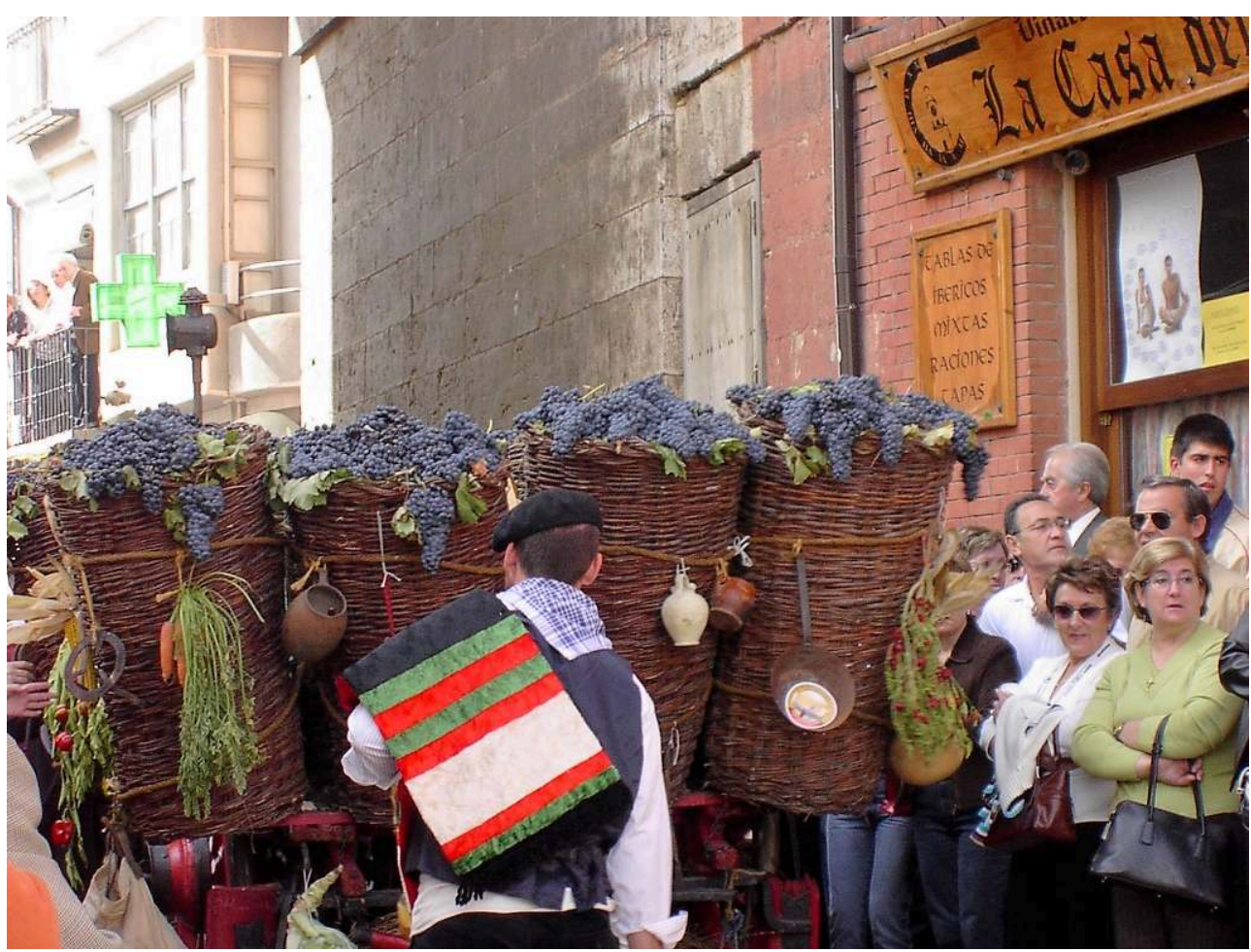

FOTOgRAFÍA DE LA AUTORA. 
5. Carros colmados de alimentos y objetos nada útiles en la vendimia tradicional, pero que se utilizan para hacer una evocación barroca del antaño y representar la riqueza que el vino ha proporcionado a los toresanos

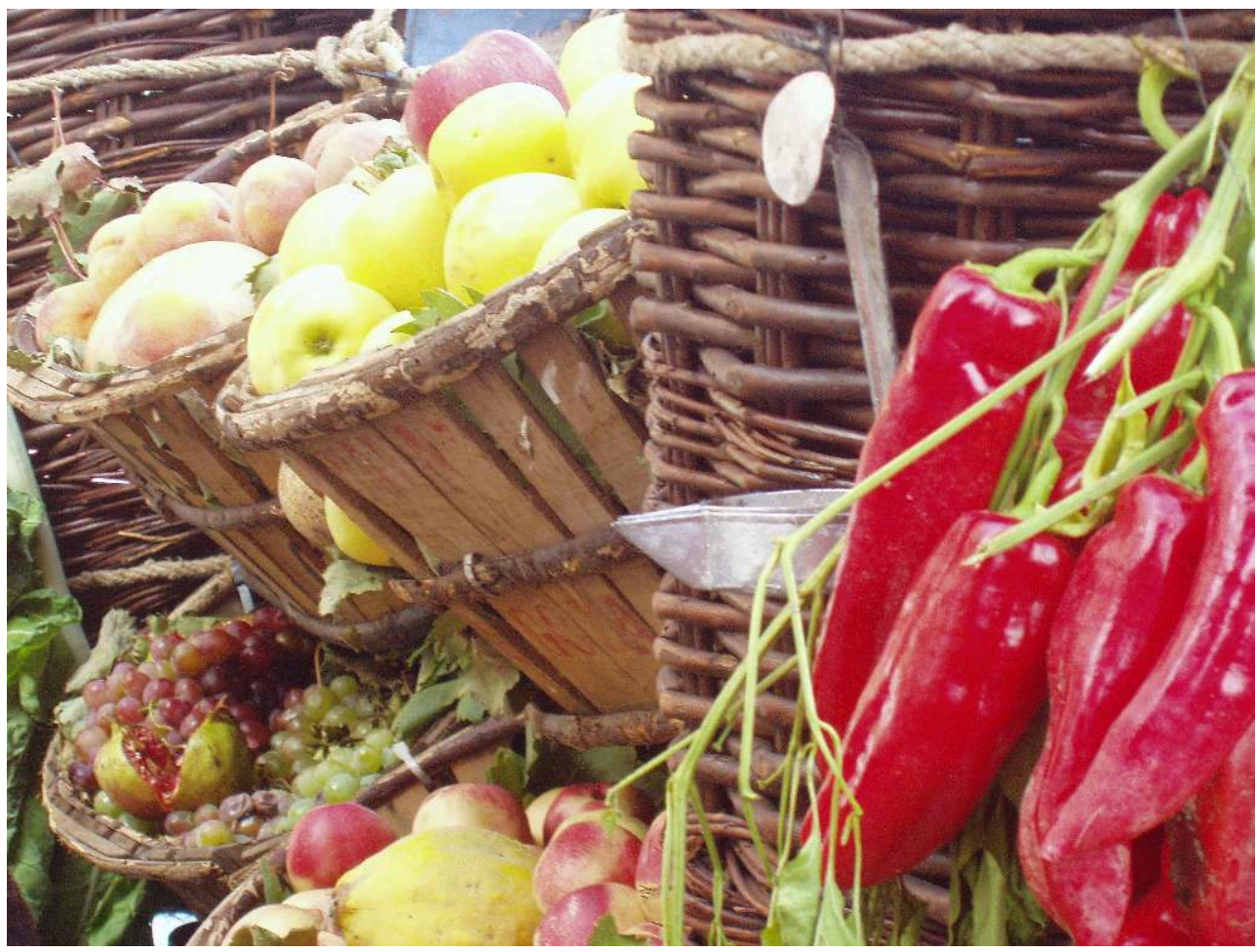

FOTOgRAFÍA DE LA AUTORA. 
6. Carros colmados de alimentos y objetos nada útiles en la vendimia tradicional, pero que se utilizan para hacer una evocación barroca del antaño y representar la riqueza que el vino ha proporcionado a los toresanos

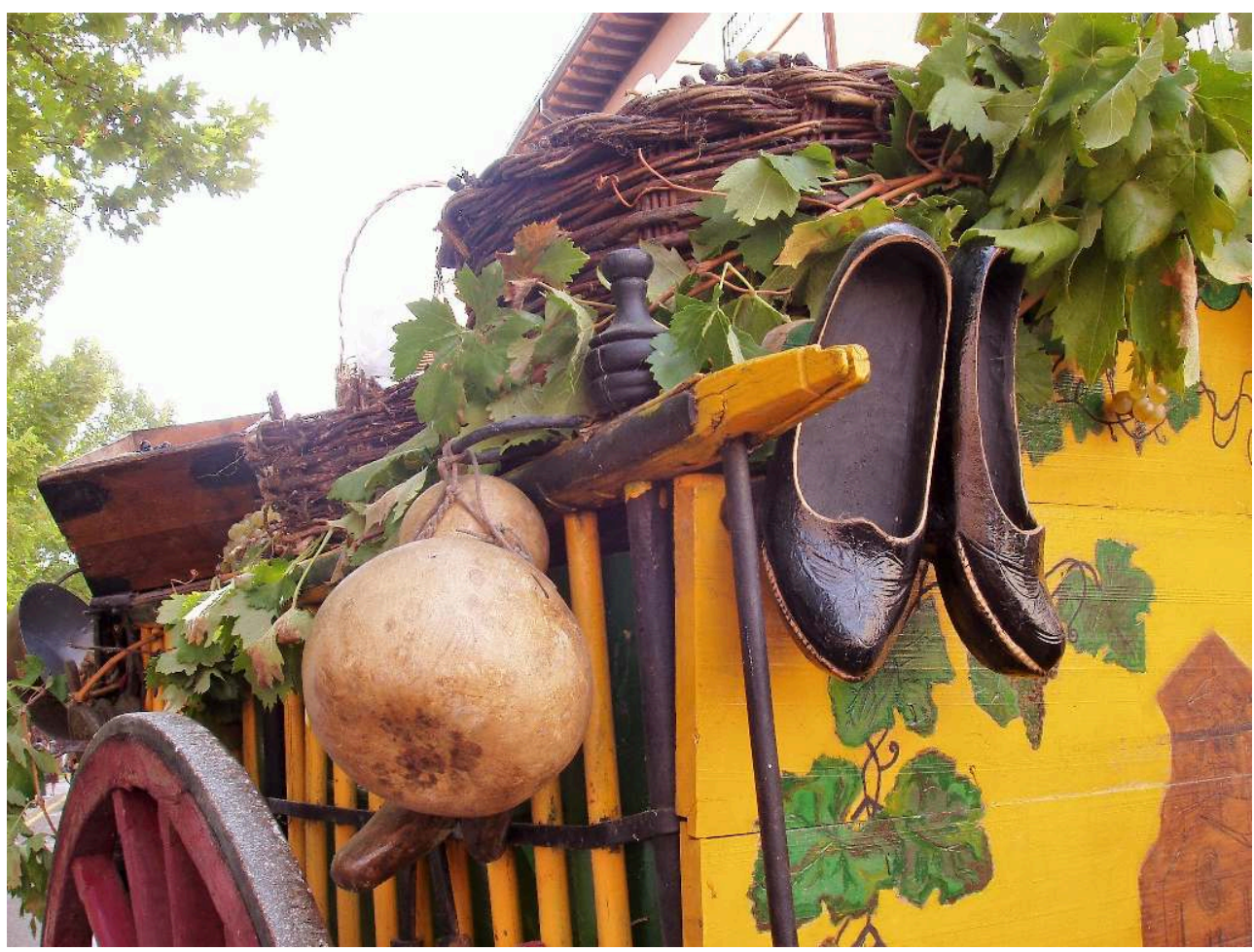

FOTOgRAFÍA DE LA AUTORA.

7. Los toresanos, cuando exaltan las faenas agrícolas en el pasado dentro del recinto urbano que estuvo amurallado, hacen presente un término extenso con pagos de labor tan importantes como Bardales que se hacen presentes en las canciones

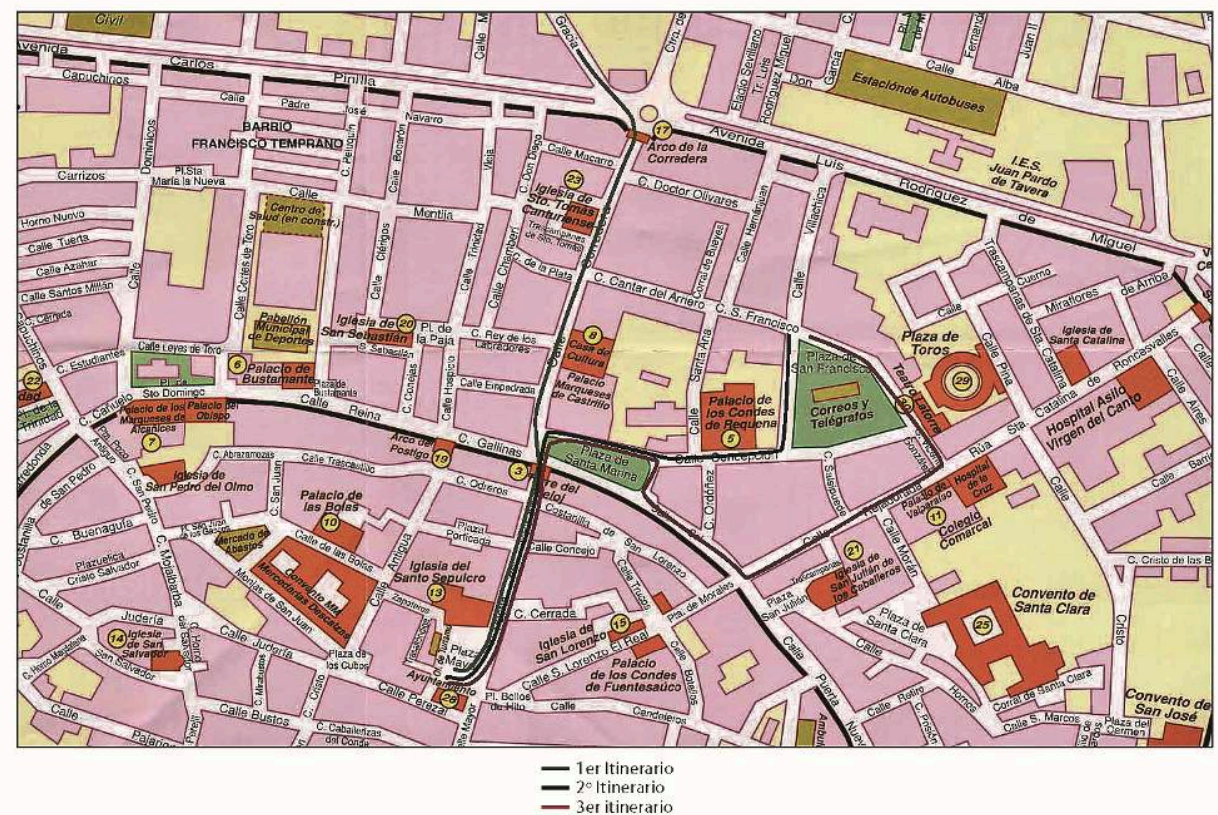

PLANO DE LA OficinA DE TURISMO dE TORO Y FOTOgRAFÍA DE LA AUTORA. 
8. Los toresanos, cuando exaltan las faenas agrícolas en el pasado dentro del recinto urbano que estuvo amurallado, hacen presente un término extenso con pagos de labor tan importantes como Bardales que se hacen presentes en las canciones

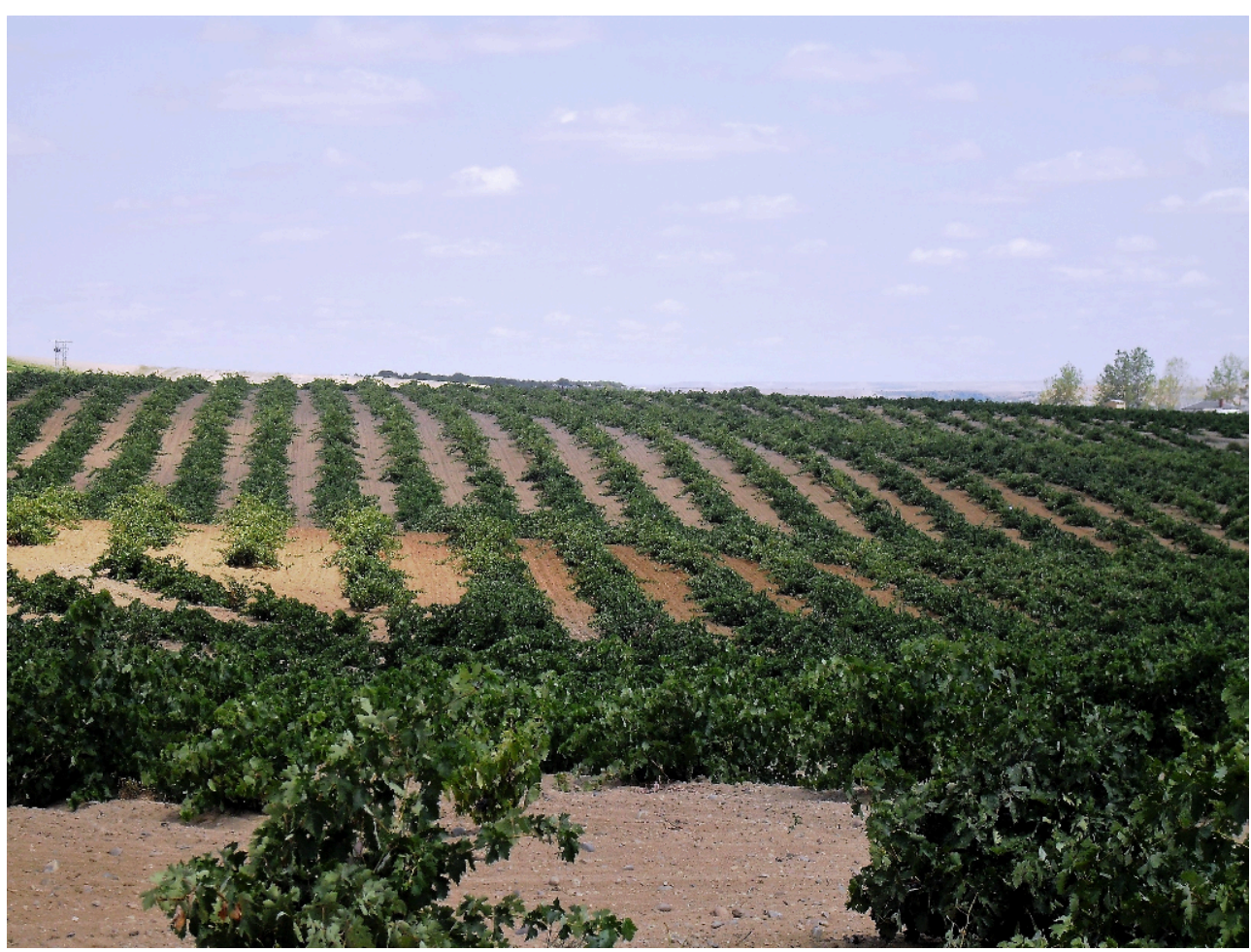

Plano de la Oficina de Turismo de Toro y fotografía de la autora.

9. Los animales limpios y engalanados contribuyen a que el desfile sea más estético

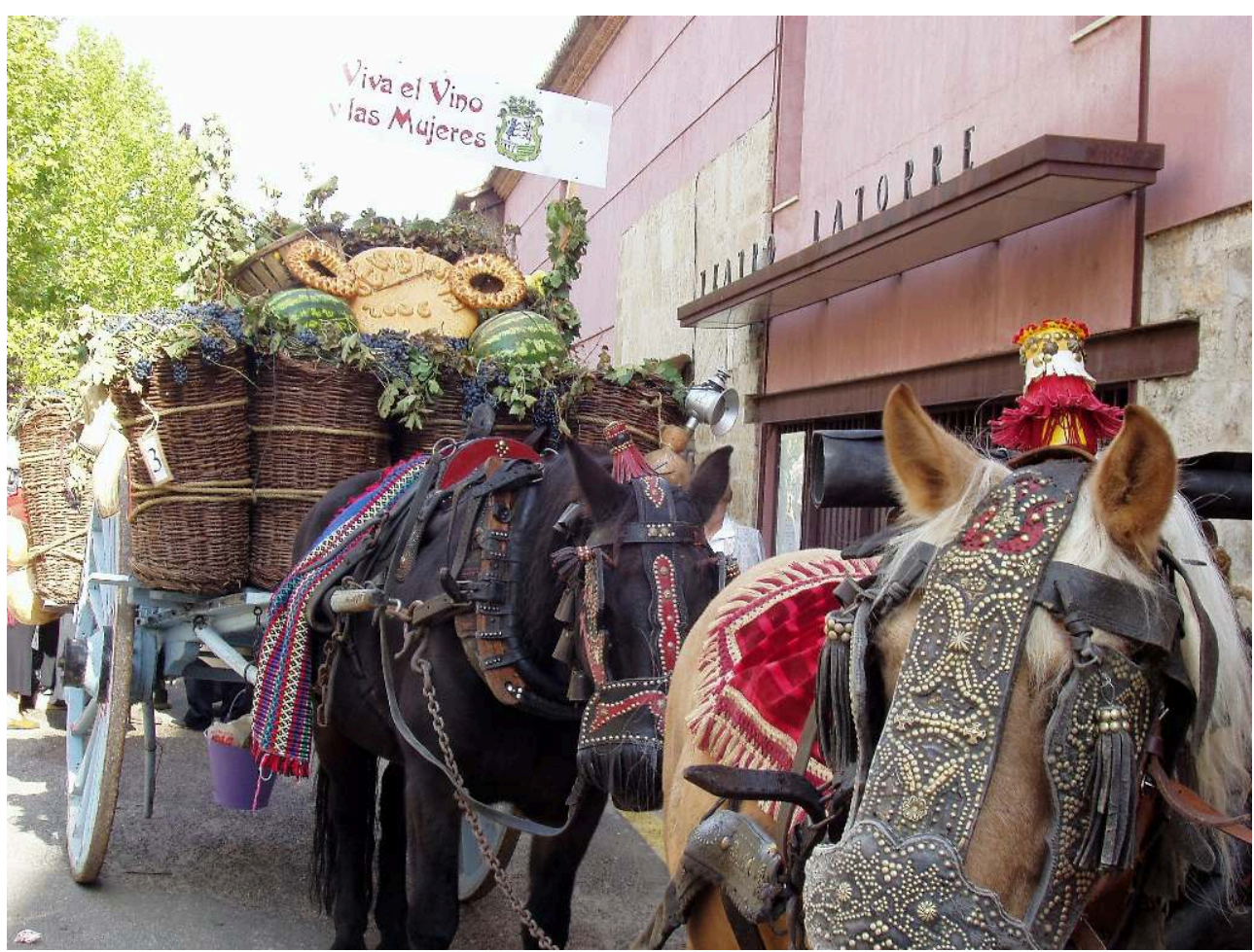

FOTOgRAFÍA DE LA AUTORA. 
10. Los animales limpios y engalanados contribuyen a que el desfile sea más estético

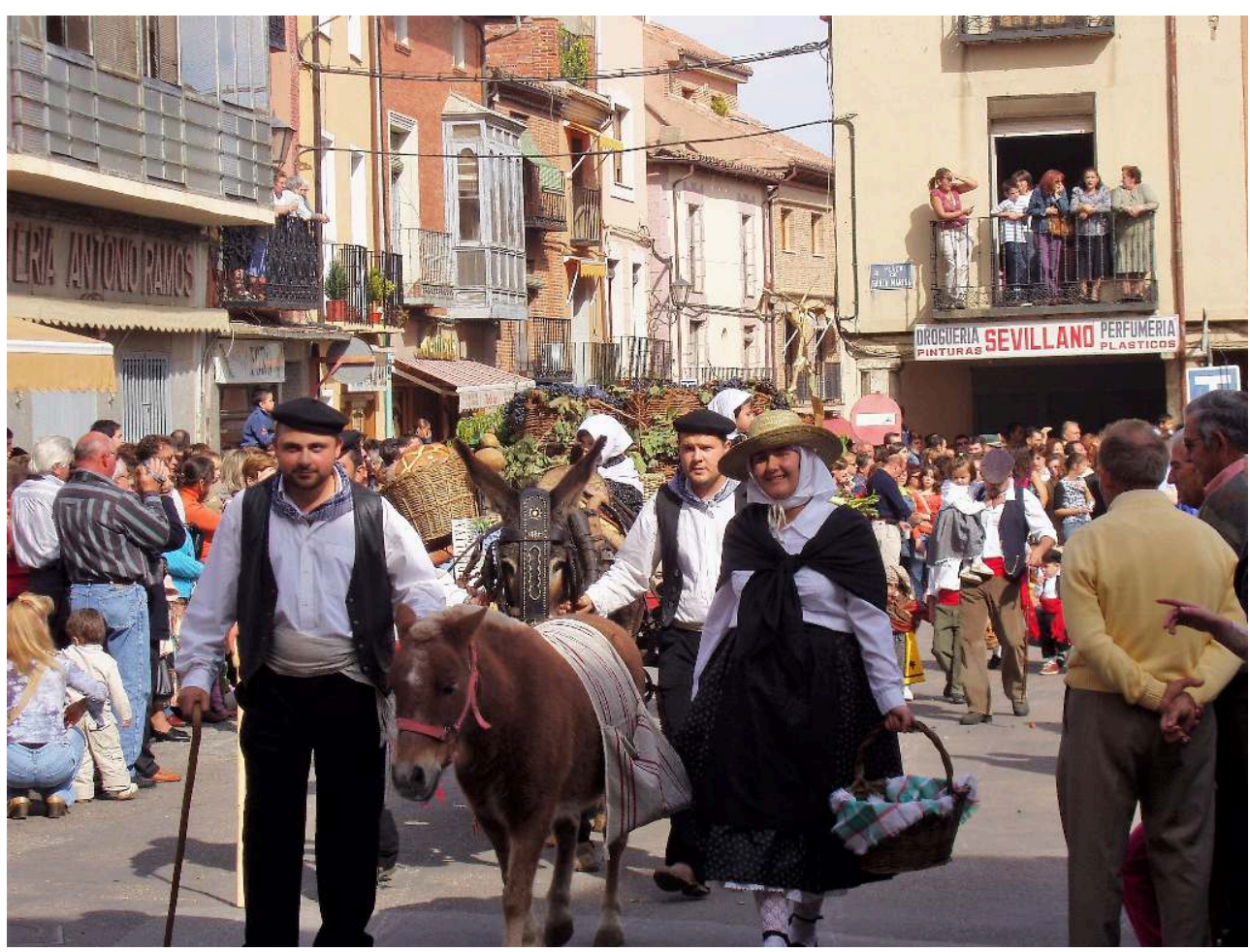

FOTOgRAFÍA DE LA AUTORA.

11. La música y los grupos de danzas tradicionales ofrecen una buena dosis de animación a un desfile de por sí alegre

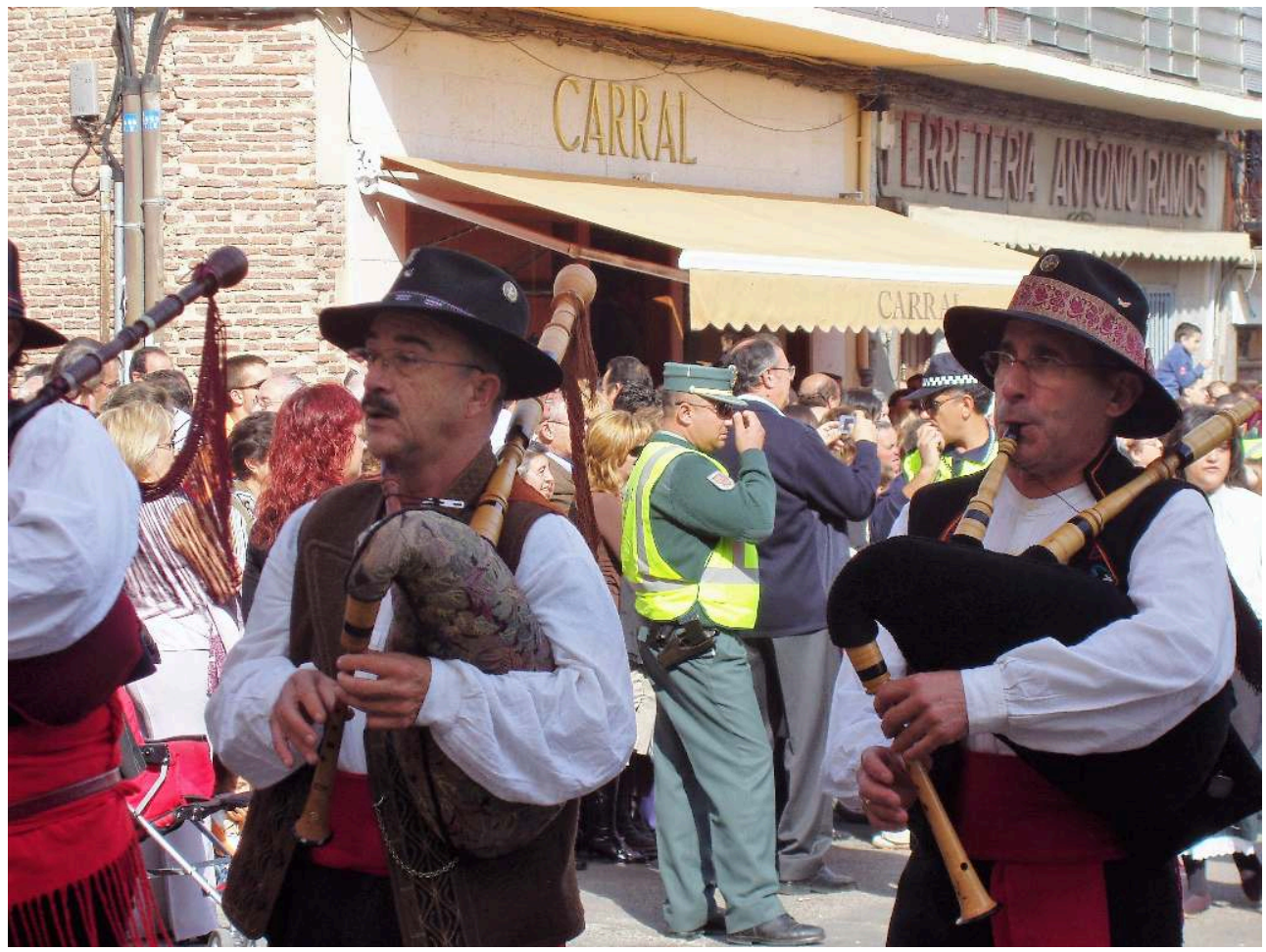

FOTOgRAFÍA DE LA AUTORA. 
12. La música y los grupos de danzas tradicionales ofrecen una buena dosis de animación a un desfile de por sí alegre.

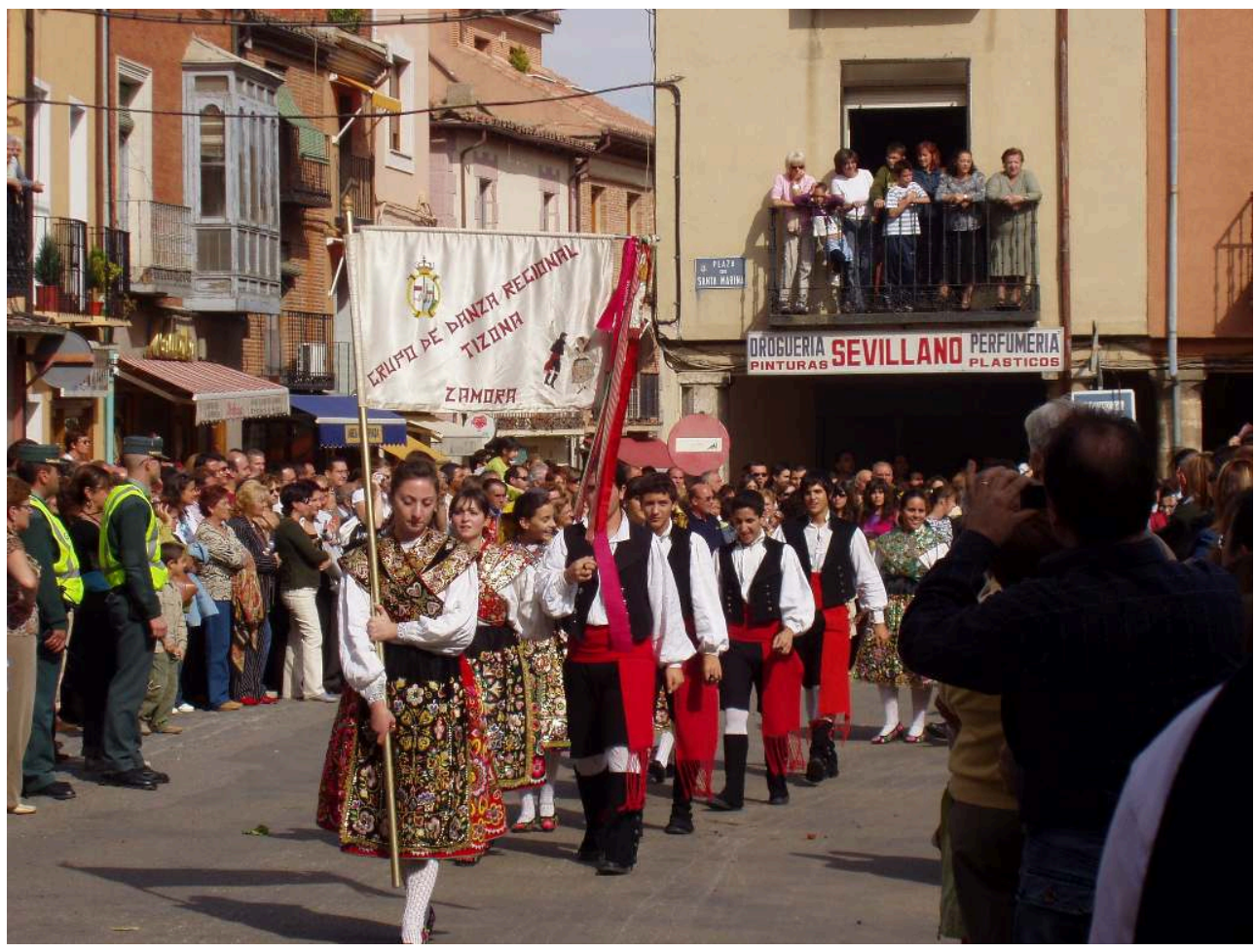

Fotografía de la autora.

13. Los elegantes trajes de "viuda rica" y de "labradora" de Toro ahora ocupan el mismo espacio y contexto que otros más modestos, algunos creados ex profeso para el desfile

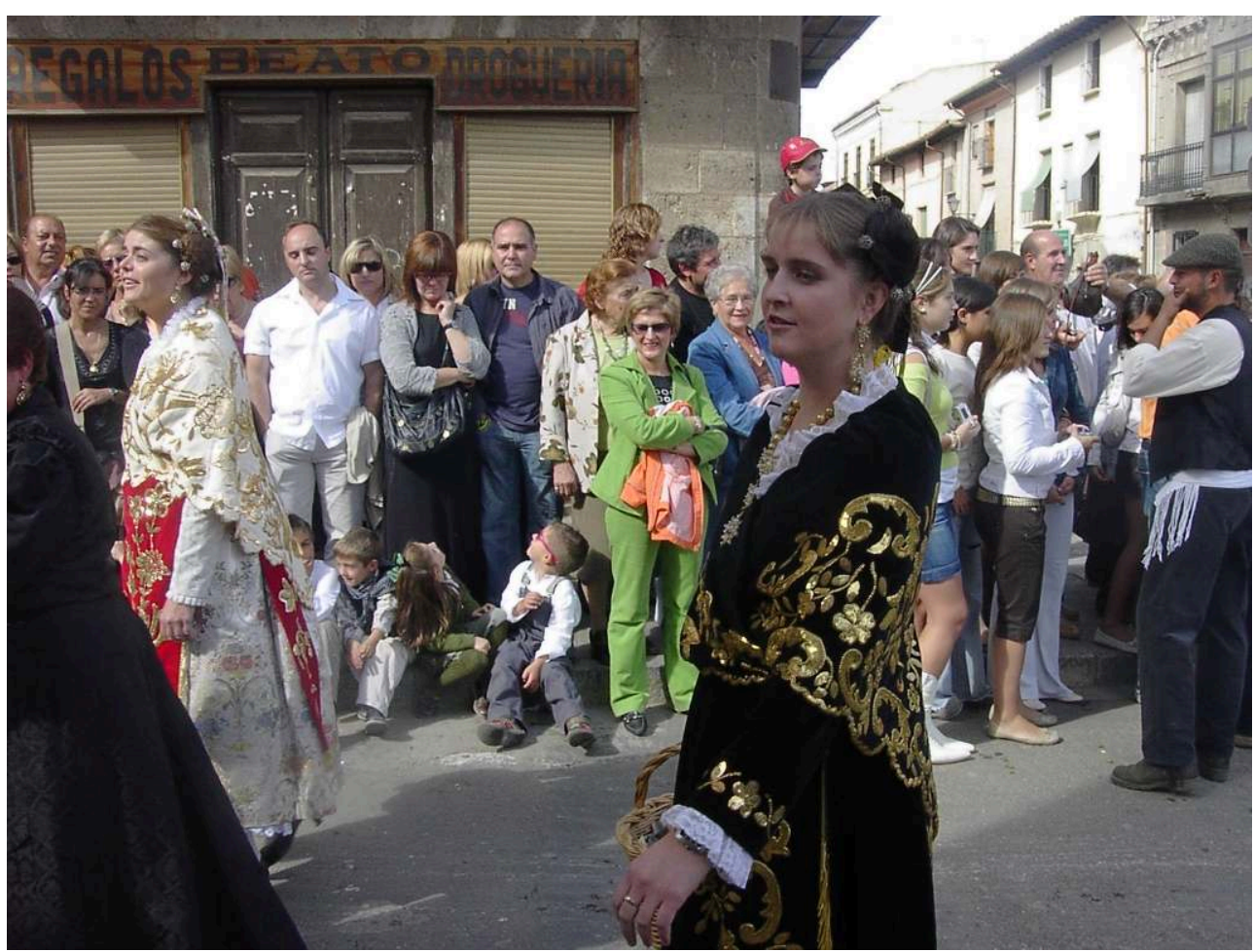

FOTOgRAFÍA DE LA AUTORA. 
14. Los elegantes trajes de "viuda rica" y de "labradora" de Toro ahora ocupan el mismo espacio y contexto que otros más modestos, algunos creados ex profeso para el desfile

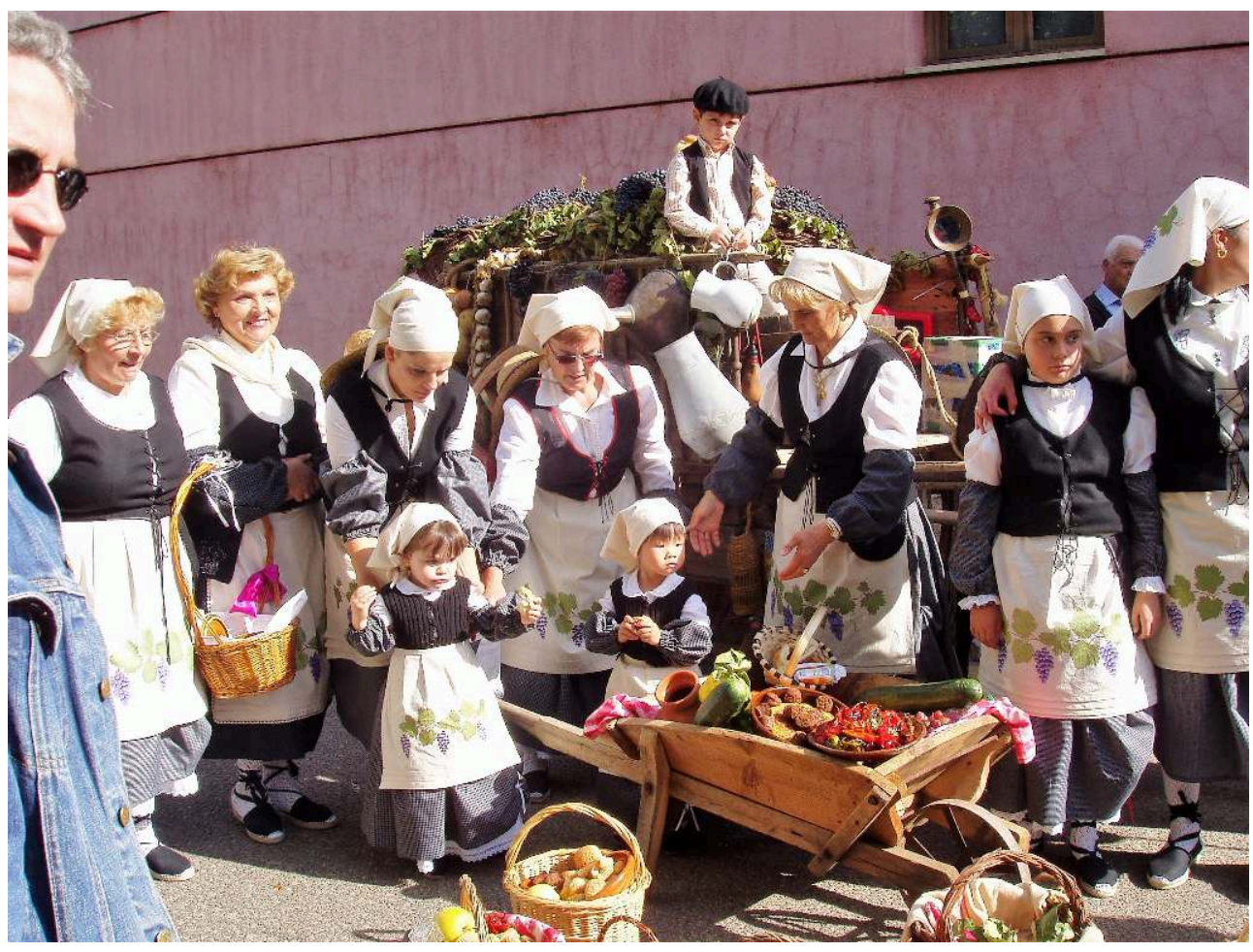

FOTOgRAFÍA DE LA AUTORA. 
15. La exaltación del pasado agrario proporciona goce y ocio en el presente frente al trabajo actual sin restricciones, pues en la fiesta pueden participar grupos de lo más diverso

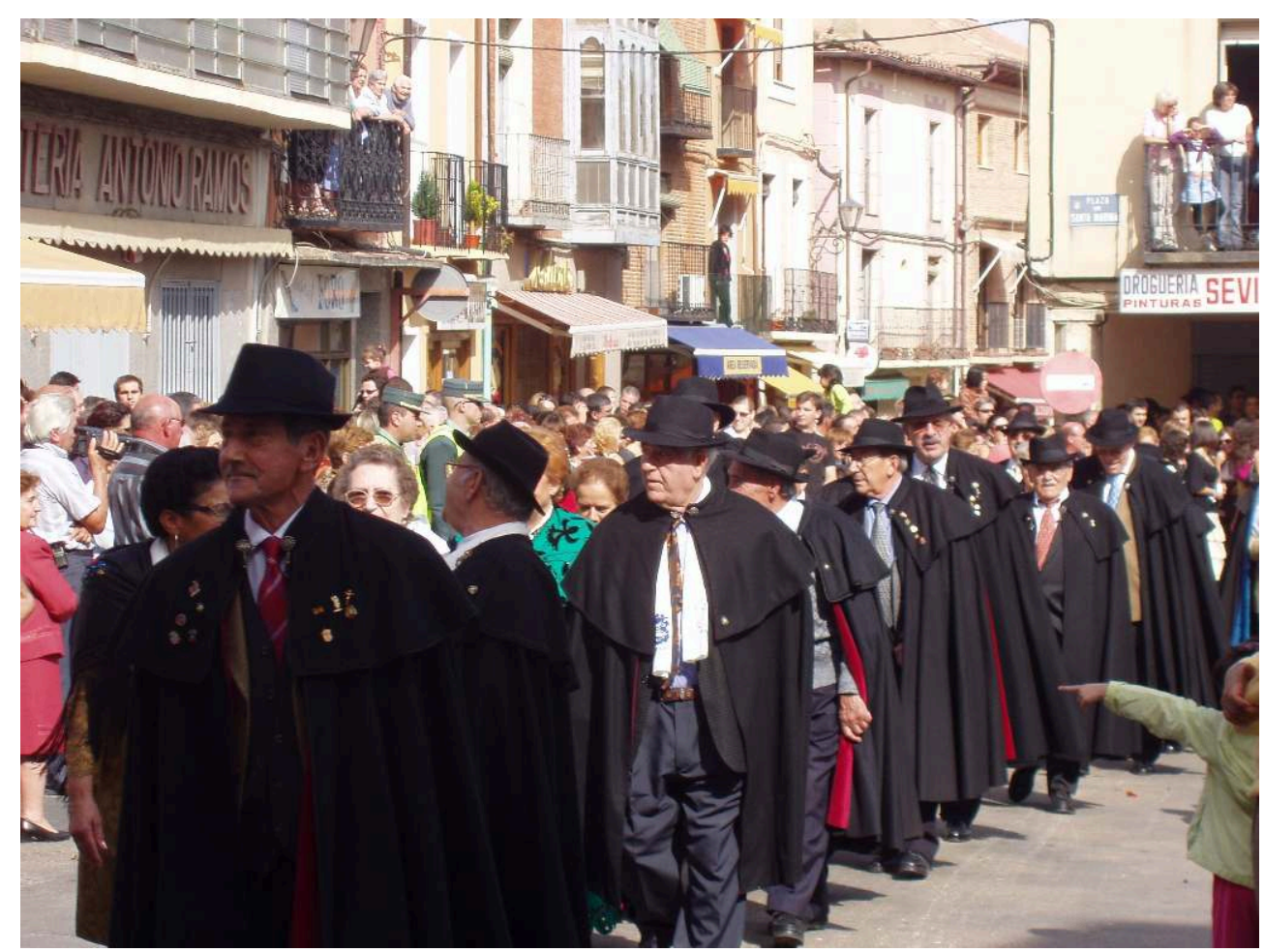

En la imagen la Asociación de Amigos de la Capa y la Banda Municipal de Toro, "La Lira". FOTOgRAFÍA DE LA AUTORA. 
16. La exaltación del pasado agrario proporciona goce y ocio en el presente frente al trabajo actual sin restricciones, pues en la fiesta pueden participar grupos de lo más diverso

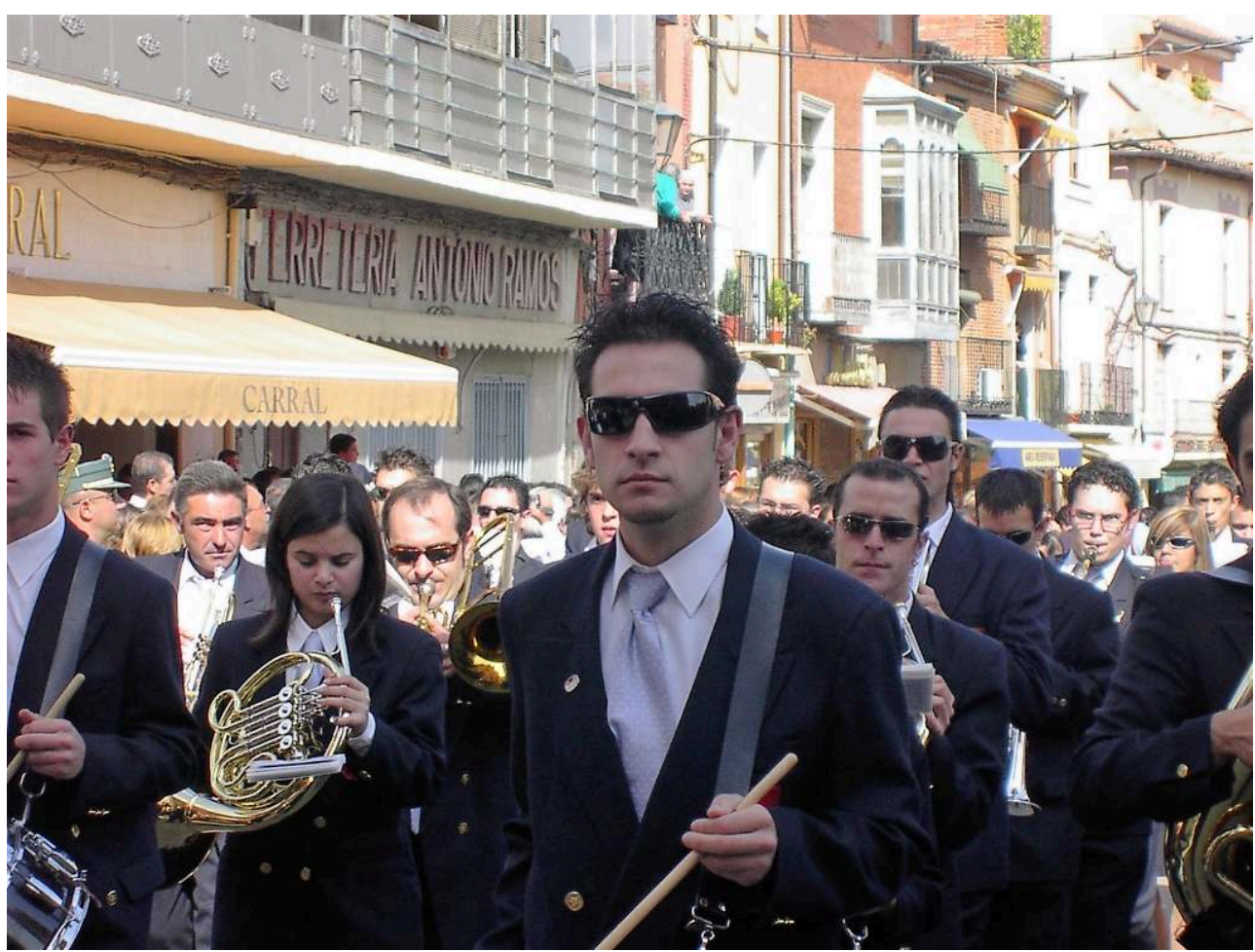

En la imagen la Asociación de Amigos de la Capa y la Banda Municipal de Toro, "La Lira". FOTOgRAFÍA DE LA AUTORA.

17. La comida comunitaria en torno al vino se convierte en Toro en un hecho social de primer orden

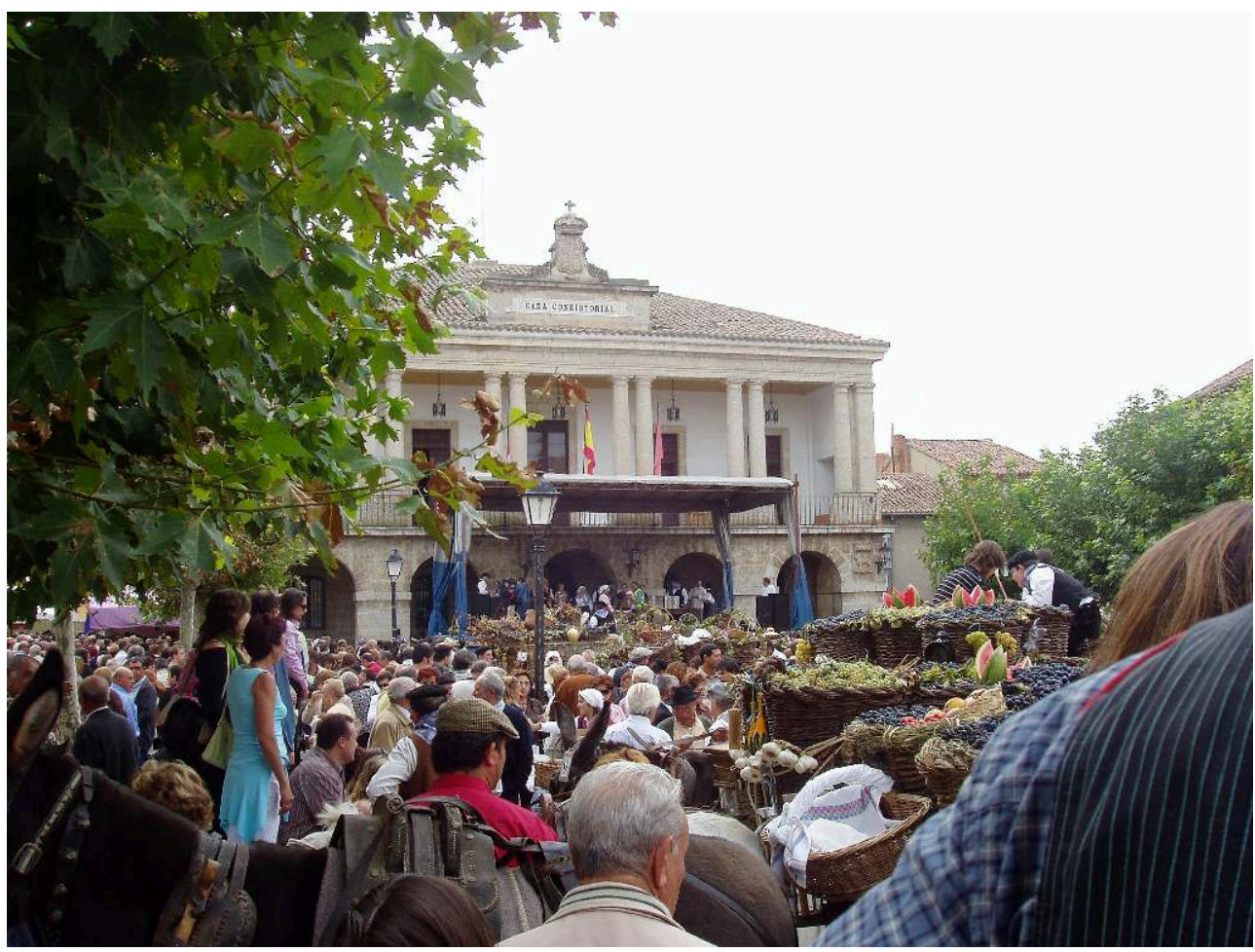

Fotografía de la autora. 


\section{NOTAS FINALES}

1. Puede consultarse: http://www.oemv.es/esp/-oemv.php

2. El mercado natural del vino de Toro era Castilla y León, el Cantábrico y Galicia. Se producían vinos muy alcohólicos, ya que la enología estaba poco desarrollada, y entonces vinos poco alcohólicos muchas veces se avinagraban. En Toro llueve muy poco y la uva madura muy bien, por lo que si se retrasaba la vendimia la uva comenzaba a pacificarse concentrándose, el azúcar, los taninos, el color y por eso los vinos tenían tantísimo tono. Estos vinos nunca se bebieron enteros, porque era vino de mezcla. Los revendedores, los que tenían almacenes para vender el vino, lo envolvían con los otros vinos que tenían y obtenían un vino final a su gusto. Eso se ha estado haciendo hasta hace unos años en esta zona, después cambió la tendencia y fue preciso adelantar la vendimia para evitar que la uva concentre tanto alcohol. Estos vinos con tanta graduación y color se conocían como vinos de capas, siendo los de siete capas los más fuertes y los mejores para la mezcla.

3. Nos referimos a todos los actos que han tenido lugar desde la edición de 2009, momento en que la fiesta ha alcanzado su máximo desarrollo puesto que en las ediciones anteriores ha habido un número menor de actos. Exceptuando los actos principales, el pregón oficial y el desfile de carros, y algunos que están muy consolidados como el Certamen de Pintura Rápida, la fiesta está abierta a incluir o a prescindir de actos en función de su aceptación popular.

4. El Ayuntamiento y el Consejo Regulador de la D. O. Toro son las dos instituciones coorganizadoras. En origen la promoción de la fiesta la hacía el Consejo Regulador, pero en la actualidad, y al menos 1999, la organización y financiación la comparte con el Ayuntamiento que destina una dotación del presupuesto municipal. Además cuenta con el apoyo del sector privado que patrocina distintos actos a cambio de publicidad. La fiesta sale adelante además por el trabajo desinteresado de algunas personas y de muchos de los participantes, pues los premios que se otorgan, aun cuando son en metálico, no son cuantiosos siendo la mayoría en especie y meramente simbólicos.

5. En Morales de Toro sí existió una celebración que cerraba el tiempo laboral de la vendimia y que se mantuvo hasta mediados del pasado siglo, aunque no tenía nada que ver con la presentación del primer mosto. Esa celebración perdida consistía en hacer unas pocas cántaras de limonada que se acompañaban de dulces y se consumían en un baile amenizado por una charanga. En ocasiones había toros. También se aprovechaba la llegada al pueblo con los carros para cantar las "relaciones", aquellos acontecimientos extraordinarios, jocosos y, a veces, vergonzosos, que habían sucedido el año anterior. Si comparamos este modo de celebrar el fin de los trabajos de vendimia en Morales de Toro, el único lugar en el que tenemos constancia de que se hacía en la zona, con la celebración actual podemos constatar que la fiesta tradicional desapareció y con el tiempo se ha implantado el modelo de la cabecera de comarca.

6. Datos publicados en La Opinión. El Correo de Zamora (15-10-2008) y en El Norte de Castilla (15-10-2008). En la Web oficial del Ayuntamiento de Toro estuvieron publicados los datos de visitantes según la Oficina de Turismo en el mes de octubre de los años 1998-2002, los años previos al reconocimiento de la fiesta como de Interés Turístico Regional y era notable el incremento de visitantes en los días de la fiesta.

7. Consiste en colocar una cuba con vino en el ruedo sobre unos maderos mientras que los mozos han de arriesgarse a conseguir la bebida burlando a un novillo que se ha soltado.

8. Suelen desfilar la Asociación de Amigos de la Capa de Toro pudiendo participar otras como la Asociación Las Candelas de Benavente, pero de facto participan grupos de lo más heterogéneo como familias completas, grupos de estudiantes, grupos de amigos, grupos de quintos, en 2008 participó una delegación oficial de la ciudad francesa de Comdom, que está hermanada con Toro.

9. El fricandón es un pisto a base de tomate, pimiento frito, tomate, pimiento y cebolla fritos con bacalao y/o patata gorda que habitualmente se almorzaba durante la vendimia. 
10. Realmente el concepto de revitalización aplicado a la labor que la Sección Femenina hizo a través de sus grupos de coros y danzas habría que matizarlo puesto que, frecuentemente, más que recuperar lo que hizo fue distorsionar la tradición en función de su ideología e intereses políticos. Además de la falta de recursos económicos y de personal que acuciaron a las cátedras encargadas de "recuperar" el corpus folklórico - danzas, canciones e indumentaria - hay que sumar constante la falta de coherencia y de rigor en la recogida de lo que el Régimen consideró una "cultura popular" apta para la formación de la mujer, que sufrió restricciones para acceder a la "cultura superior". En sus métodos de recopilación del folklore primó lo cuantitativo sobre lo cualitativo, y, a pesar de los escollos, la indumentaria y los coros y danzas, afianzaron los logros que la organización utilizó para adoctrinar-relegar a la población femenina (Casero 2000).

\section{RESÚMENES}

Cada año en octubre en la ciudad de Toro (España) se celebra la Fiesta de la vendimia, que tiene su clímax en el conocido popularmente como "Desfile de carros". Esta fiesta de exaltación del vino, medicina y alimento importantísimo en las economías de subsistencia por su alto aporte calórico, pero que en la actualidad se consume como un producto de moda, es el marco ideal para representar la identidad toresana. Durante el desfile el centro de la ciudad se convierte en el escenario de una puesta en escena del patrimonio cultural vitivinícola tradicional, aunque en la historia reciente se han producido multitud de cambios que hacen que lo que se percibe como tradicional sea la evocación romántica de un mundo desaparecido. Esta performance está avalada y legitimada por una altísima participación y por el consentimiento del grupo que lo organiza y participa año tras año.

Every year in October in the city of Toro (Spain) is celebrated the Festival of the grape harvest, which has its climax in the popularly known as "Carriage Parade". This feast of exaltation of wine, medicine and important food in the subsistence economies due to its high caloric intake, but which is now consumed as a fashionable product, is the ideal framework for representing the toresana identity. During the parade the center of the city becomes the scene of a staging of the traditional cultural heritage of wine, although in recent history there have been many changes that make what is perceived as traditional is the romantic evocation of a World disappeared. This performance is endorsed and legitimized by a very high participation and by the consent of the group that organizes it and participates year after year.

\section{ÍNDICE}

Keywords: ethnicity, grape harvest, traditional culture, party, dramatization

Palabras claves: etnicidad, vendimia, vultura tradicional, fiesta, evocación del pasado

\section{AUTOR}

\section{MARIA PILAR PANERO GARCÍA}

Universidad de Valladolid, España mariapilar.panero[at]uva.es 